\title{
La calidad como yacimiento de la nueva gestión pública: la experiencia del Instituto Nacional de la Seguridad Social
}

Vicente Pérez Menayo *

\section{Gestionar con calidad en la "Nueva Era"}

\section{La "lógica borrosa"}

Estamos en un momento crucial. Experimentamos un período de cambio sin precedentes en la historia de la humanidad. Al principio, los cambios parecían abrumadores e incomprensibles. Durante las décadas de 1960 y 1970, muchos de nosotros sentíamos que alboreaba una Nueva Era (New Age), pero no comprendíamos del todo qué estaba sucediendo y por qué (ToFflER, 1980; Ferguson, 1985; NaISBiTT, 1990; Garland, 1996). Fue sólo en la década de 1980 cuando comenzamos a percibir el curso y la magnitud del cambio en la sociedad civil y las presiones externas que emergían sobre el Sector Público (ver figura 1).

De hecho, experimentamos un cambio radical de paradigma. Estamos desarrollando una estructura conceptual nueva para considerar al mundo y a nuestro lugar en él. Esta propuesta reciente del pensamiento está en el mismo centro de la Nueva Era. Estamos apartándonos del pensamiento lineal y determinista, hacia una nueva interpretación de la vida organizativa sobre la base de conceptos de unidad e integración, revitalizando el pensamiento sistémico (Garde Roca y Pérez Menayo, 1996). Pero, a su vez, un mundo de mayor diversidad y complejidad y, paradójicamente, que afirma lo distintivo y lo particular; así aparece, además, una nueva categoría de ciudadano con capacidad de autoorganización, reglas particulares y comportamientos comunes.
La experiencia del Siglo XX nos hace pensar que es más eficaz y efectivo permitir al individuo que tome decisiones y logre objetivos con su propio esfuerzo, y no mediante una planificación estatal centralizada (NAISBITT, 1998). Al encontrarse la tecnología en todas partes, las personas pueden encontrar formas más rápidas, eficaces y pragmáticas de lograr sus objetivos y seguir sus propios intereses. Podemos afirmar, continua NAISBITT, que el amanecer de la era de la información y la globalización completa la trasferencia de poder desde las instituciones a los individuos y sus redes.

Como vaticina el Club de Roma (1998) todo eso permite imaginar la existencia de un futuro Estado virtual, con sus propios ciudadanos, sus propias relaciones de poder, sus propios objetivos y su propia y legítima soberanía (la naturaleza autoorganizativa de Internet nos indica la dirección que sigue el mundo). Parece que muchas administraciones públicas tardan en comprender el cambio; las burocracias, por definición, se resisten a él y creen que oponerse es sobrevivir; pero no se puede gobernar de espaldas a la sociedad global de la información. La llamada reinvención del Estado no es posible sin la reinvención del sistema de prestaciones del mismo y, por tanto, sin una reducción drástica de los costes y una mejora de los servicios que el sector público presta a sus clientes (TAPSCOTT, 1998).

No cabe duda de que asistimos a un cambio de funciones en el sector privado y en el sector público. La introducción de nuevas tecnologías siempre ha tenido como resultado cambios sociales. La diferencia reside esta vez, asevera NAISBITT (1998), en que mientras la tecnología ha avanzado vertiginosamente, los cambios sociales no han podido seguir el mismo ritmo. De hecho, existe una distancia cada vez mayor entre el cambio so- 


\section{Fisegrara 11

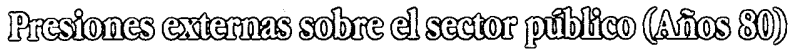

Notable CRECIMIENTO Y COMPLEJIDAD de funciones del Sector Público.

CAMBIO DE VALORES de la sociedad hacia una mayor autorrealización.

Un PROCESO DE CONTINUA MEJORA de la participación como legítima demanda de los ciudadanos.

Necesidad de DESARROLLO DE LAS COMPETENCIAS del Sector Público con una DESCENTRALIZACIÓN del tratamiento de los problemas para asegurar la acogida y satisfacción de la sociedad: «ESTADO COOPERATIVO.

Creciente deseo de los ciudadanos de poder .CONSUMIR: LA PRODUCCIÓN DEL SECTOR PÚBLICO DE MANERA SEMEJANTE A LA DEL SECTOR PRIVADO y de experimentar la .CALIDAD. como un atributo de la ePRODUCCIÓN. así como del modo en que se prestan los SERVICIOS.

Fuente: Elaboración propia y Helmut KLAGES (1995).

cial y el cambio tecnológico. Se pregunta NaISBIT: ¿cómo solucionamos la tensión creativa entre la alta tecnología (bigh tech) y la necesidad, cada vez más sentida, del alto contacto humano, la atención personalizada (bigh touch)? La comprensión de estos fenómenos sociales ayudará a las organizaciones a entender de forma más eficaz las necesidades tanto de sus empleados como de sus clientes. Para que la sociedad funcione, el sector público también debe funcionar eficazmente. Por lo tanto, es necesario que este sector se adapte a los requerimientos del Management de la Nueva Era y adopte los enfoques emergentes, que, con lentitud y con algo de renuencia, son aceptados en las entidades de negocio (Garland, 1996).

Peter DRUCKER ha afirmado durante medio siglo que el lugar donde más se necesita la teoría del management es en el sector público; incluso los cínicos tienen que admitir que estas herramientas de gestión difícilmente vayan a poner peor a las administraciones públicas. Las circunstancias peculiares del sector público no han hecho más que exagerar las contradicciones con la teoría de la gestión del sector privado; y ha habido muy poca teoría de la gestión buena y nueva para el sector público (MICKLETHWAIT y WoOLDRIDGE, 1998). Ahora bien, ante la adopción de cualquier modelo de gestión de calidad, u otra herramienta managerial susceptible de utilización en el entorno público, el autor de este trabajo sugiere la aplicación de la lógica borrosa (MaCNenl y FREBBERGER, 1998). La lógica aristotélica preconiza que toda afirmación debe ser verdadera o falsa, sin téminos medios y ha inspirado nuestros modelos mentales (SENGE, 1992, 1995) hasta bien entrado el siglo XX. No obstante, la vida de las organizaciones no es blanca o negra; es más bien una gama sutil de grises.

La lógica borrosa estriba en admitir la existencia de lo vago, de los contomos indefinidos, a reconocer la incertidumbre, a dar vali- dez a las contradicciones. La lógica borrosa es la formulación científica y tecnológica de la multivalencia. Detrás de ella una filosofia: el derecho a contradecirse, a no definirse con contundencia, a no categorizar y a utilizar la palabra depende (Kosko, 1998). Este enfoque inspira las páginas que siguen en cuanto al empleo de las estrategias y modelos de calidad en las organizaciones públicas.

\section{Calidad eficiente y escenarios de austeridad}

La satisfacción con calidad de las nuevas necesidades sociales abre una vía innovadora para la aplicación de nuevos conceptos. Recientemente ha aparecido el término yacimiento, aplicado al mercado de trabajo, originado respectivamente de los vocablos jaciment y sources. El tiempo y las convenciones han ido favoreciendo la utilización del término yacimiento (Jiménez, BarReiro y Sánchez, 1998). Me ha parecido oportuno aplicar esta acepción a la calidad porque recoge dos ideas que conviene retener: por una parte, la gestión de calidad es una estrategia no utilizada con carácter general en las organizaciones públicas, es una nueva fuente para la gestión pública; y, por otra, es necesario un esfuerzo de conceptualización, de detección y de remoción de los obstáculos que posibiliten su aplicación.

Históricamente, la Administración Pública, basada en la asignación jerárquica de bienes y servicios, y el mercado, surgido de los intercambios individuales, se han configurado como medios alternativos y complementarios para la satisfacción de las necesidades sociales. La transición hacia el mercado de los servicios públicos emerge como una alternativa ideológica y económica al predominio de la asignación burocrática, que caracteriza el Estado de Bienestar. Así, una idea central ha de ser la eficiencia en la producción de los bienes públicos y el referente para medirla el consumidor de tales bienes, ya que como se ha afirmado una cosa es el Estado del Bienestar y otra el bienestar del Estado (de sus servidores)n (ECHEvarRía, 1993).

En realidad, la idea del acercamiento al consumidor se ha introducido en el sector público con fines aparentemente muy distintos: aumentar la eficiencia, recortar los gastos, mejorar la imagen, motivar al personal, y, en términos más generales, mejorar la calidad de los servicios públicos.

Muchas iniciativas de ajuste desde los años 80 han supuesto que el problema era el tamaño de la Administración o su ineficiencia. El contexto en la actualidad es la incertidumbre y los recursos seriamente escasos. Ante esto un comportamiento repetitivo (más de lo mismo) refleja una respuesta determinada, con reajustes continuos, exceso de gasto sobre lo autorizado, poca credibilidad en las estimaciones. Para evitar estas situaciones era necesario adaptar el sistema a la realidad (políicas de contención del gasto). Según la combinación de los elementos o 
variables certidumbre-incertidumbre y disponibilidad frente a tos de respuesta a las cuatro situaciones o alternativas descritas escasez de recursos aparecen cuatro diferentes comportamien- por WILDAVSKY (1975) —ver figura 2-.

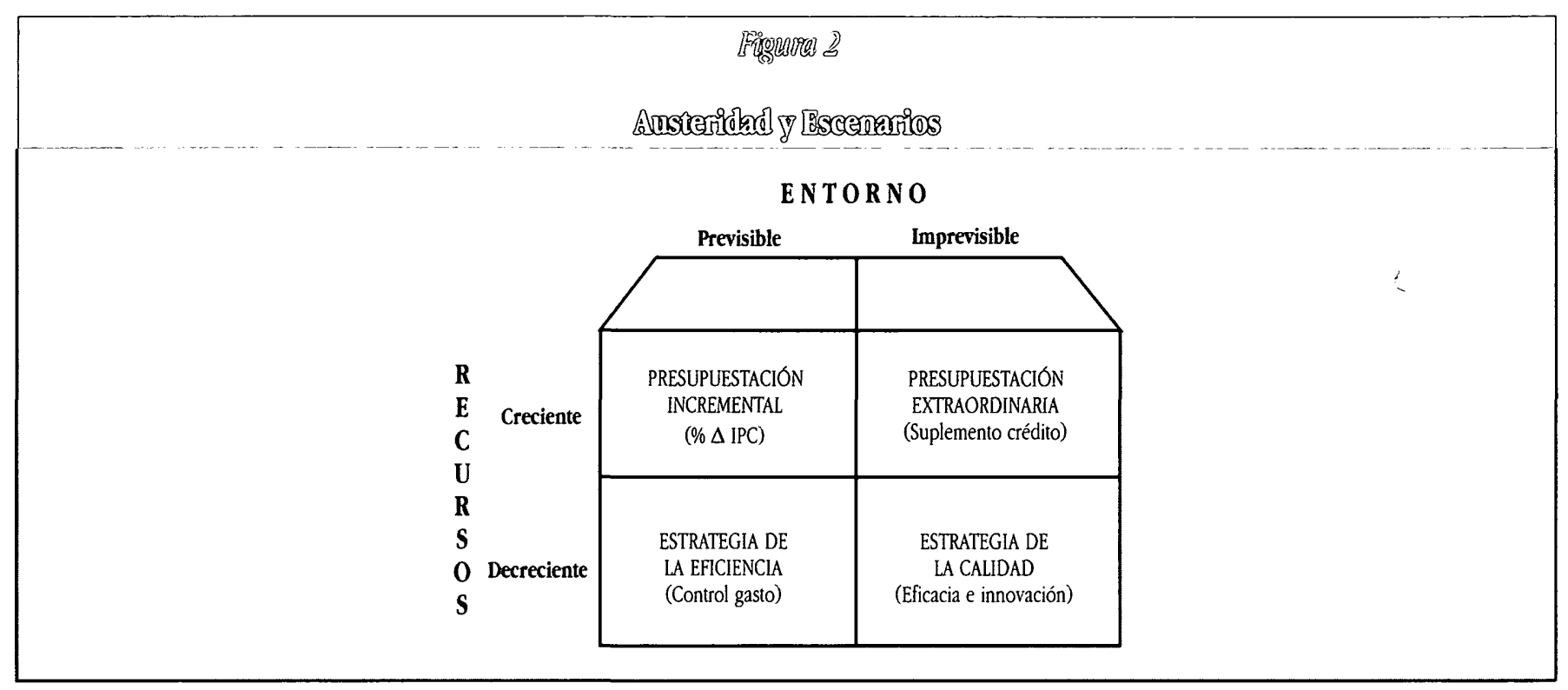

Fuente: Elaboración propia y WIIDAvSKY (1975).

En situación de recursos disponibles y certidumbre respecto a los problemas con que se enfrenta el sector público, la adaptación exigiría simplemente realizar un presupuesto incrementalista: la continuidad del sistema está garantizada por la asignación de recursos, no por la satisfacción de necesidades reales. En una situación de cambios, de presiones y nuevas demandas, el comportamiento sería de presupuesto suplementario: no responde a un análisis general de opciones y prioridades, es una contingencia del momento. Un tercer contexto sería de recursos escasos en situación de certidumbre: la respuesta es la estrategia de la eficiencia (recortes presupuestarios, descentralización, especialización en la gestión de los servicios, estandarización, compromiso de productividad, exigencia de responsabilidad). En este grupo de comportamientos había que englobar los movimientos modernizadores en Europa desde los años 80 .

Sobre la variable recursos decrecientes se comienzan a desarrollar comportamientos adaptativos de aproximación a la calidad. La calidad en el escenario tercero es un medio para conseguir más productividad y controlar el gasto sin provocar resistencias. Son las estrategias de calidad que operan de arriba abajo, con la fuerza de disposiciones legales dictadas y publicadas con frecuentes contradicciones entre objetivos de cantidad y calidad y sin apoyo real de las personas encargadas de su realización última. Todo se reduce a indicadores, ratios, ahorros macro y estadísticas. Como el entorno es previsible se espera que las series largas de indicadores confirmen la tendencia que ya se conocía de antemano porque no puede haber sorpresas. Si no se consi- guen ahorros, es que ha fallado la autoridad y es necesario reforzarla.

Es en el último escenario de incertidumbre y recursos decrecientes donde las estrategias de calidad pueden responder a los retos planteados a las Administraciones Públicas: capacidad para el diseño e implantación de un nuevo marco de relaciones, que sustituya al sistema tradicional de responsabilidad por un sistema de análisis en común y aprendizaje colectivo; la innovación y la eficacia hacen referencia a la flexibilidad, lo cualitativo, y la superación y prevención de las deficiencias; después de saber que las hay y dónde se localizan, se pueden superar mediante un proceso de mejora continua.

Desde un punto de vista sociológico, la oportunidad de este nuevo enfoque de la calidad, tiene en cuenta las demandas de calidad en el servicio publico, formuladas cada vez más por los ciudadanos en comparación con los niveles de calidad exigidos al sector privado. Actualmente existe una baja aceptación social de la mala calidad; ya no podemos vivir con los niveles habitualmente aceptados de demoras y errores y materiales y mano de obra defectuosos (Deming, 1989). Como afirma Crosby (1987), el mayor coste no es la calidad sino su falta: "la calidad no cuestan; lo que cuesta dinero son los servicios que no tienen calidad, todas las acciones que resultan de no hacer las cosas bien desde la primera vez. La calidad no sólo no cuesta, sino que es una auténtica generadora de utilidades. El mayor coste de la calidad es el que se gasta en hacer los trabajos mal, es el volver a prestar otra vez el servicio, en definitiva, incorporar la mala calidad a la organización. 
La evaluación de los costes de la no calidad es probablemente la herramienta más eficaz para detectar las deficiencias y priorizar los planes para eliminarlos.

Como apuntan MickIETHWAIT y WOOLDRIDGE (1998), se ha convertido en una verdadera militancia de los gobiernos de cualquier ideología el lógico deseo de hacer más con menos: seguir ofreciendo unos servicios públicos razonables sin emplear una mayor proporción de PIB en el Estado; así pues, es perfectamente lógico que los responsables políticos hayan llegado a la conclusión de que pueden dejar de tomar decisiones impopulares sobre la subida de los impuestos o la reducción de servicios gestionando mejor las cosas. Las organizaciones que administran recursos públicos no pueden mantenerse al margen de estos enfoques y las estrategias de calidad pueden coadyuvar a las exigencias, de ahora en adelante permanentes, de eficiencia en el sector público, pero no como un discurso retórico sino como una exigencia de la sociedad civil respecto al papel de las Administraciones Públicas.

\section{La renovación del sector público como exigencia de competitividad}

En la Unión Europea, se considera esencial para la economía nacional la renovación del sector público. Las Administraciones Públicas de los países desarrollados evolucionan cada vez más deprisa porque no tienen elección y porque existe, entre otras, una razón que les induce a hacerlo: el paso de un universo cerrado y dirigista a un universo abierto y competidor. La mundialización de los intercambios sitúa a los Estados, y a su agregado público, en situación de competir a escala de los grandes bloques económicos. La mutación interna de la Administración es una condición de competitividad para la nación. Además, a medida que entramos en la dinámica de Maastricht, nuestras decisiones se hallan cada vez más sometidas a la apreciación del juez comunitario (SERIEYX, 1994).

Como apunta AzUa Mendia (1991), los parámetros definidos como productividad y calidad aparecen hoy como privilegiados por los analistas para explicar la competitividad cuyo objetivo principal es satisfacer oportunamente las expectativas del mercado. En efecto, la permanencia en este mercado se consigue por el equilibrio dinámico de la competitividad, término que puede ser traducido también por el de supervivencia cuando se aplica a empresas, sectores o sistemas industriales.

Para muchos observadores parece existir una crisis de fe en el sector público y el resurgir de la fe en el privado. Ante el debate relativo al achicamiento del Estado, Estado minimo, Estado modesto, cabe ahora preguntarse si la supervivencia sólo atañe al ámbito empresarial privado, obligado, por otra parte, a estrategias de calidad total sino quiere sucumbir ante la competen- cia. Como afirma TAPsCotT (1998), "El sector público está sitiado en todo el mundo. Los contribuyentes de todas partes quieren un Estado mejor y más barato. El mensaje es sencillo: hacer pequeños ajustes al sistema no basta. Lo que hace falta es reinventar enteramente el Estado. Instalar la tecnología en un cuerpo político disfuncional no resolverá el problema. Pero si se conciben adecuadamente, las redes pueden ser cruciales para mejorar la tarea del gobiemo. Los programas gubemamentales se pueden distribuir electrónicamente a través de la red (CEBRIÁN, 1998), y así mejorar la calidad y reducir los costes. Se puede facilitar el acceso a la información oficial y crear así un gobiemo más abierto ("Estado cooperativo" en acepción de HIEl, 1993). Los departamentos virtuales pueden combinar el trabajo de muchos organismos para ofrecer una ventanilla única a los ciudadanos. A través de las redes, se puede acabar con la burocracian (ver figura 3).

\section{Irignom}

\section{astaro Corperathvom}

TRADICIONALMENTE: se suponía que en la ADOPCIÓN DE DECISIONES PÚBLICAS se tenían en cuenta los intereses de la sociedad frente a unos antecedentes de unas estructuras encorsetadas por leyes y reglamentos.

ACTUALMENTE: comprende planteamientos cercanos a ADOPCIÓN DE DECISIONES CONJUNTAS (PÚBLICO/PRIVADA) que puede apuntar a la creación interactiva de normas y reglamentos aptos para hacer frente a las expectativas de calidad del exterior.

Fuente: Elaboración propia y HiEl (1993).

Ésta es otra razón que avala la aplicación de estrategias de calidad en el contexto de una Nueva Gestión Pública, ya que además de controlar las que Farlie (1968) denominaba "Políticas de Apetito Nacional Bruto", el sector público ha de moverse con los tiempos. Al igual que el sector privado ha de tener en cuenta la propagación de la tecnología de la información y la aparición de unos consumidores mucho más exigentes y conscientes de su rol. Al Gore se quejó en una ocasión de que los norteamericanos tenía que soportar sun gobiemo que escribe con pluma de ganso en la era del Word Perfect. (MickleTHWAit, 1998).

En efecto, el consumidor en general se está defendiendo y esta tendencia progresa también para el consumidor de servicios públicos. Como señala POPCORN (1993), era inevitable: la generación rebelde llegó a la mayoría de edad como la generación de los superconsumidores. Confrontados diariamente con la calidad deficiente, la irresponsabilidad y las afirmaciones fraudulentas, los consumidores levantaron la bandera de la protesta contra la falta de ética comercial. Esta injusticia social ha dado lugar a una nueva generación de rebeldes: la de los consumidores vigilantes. Esta tendencia del consumidor a ejercer una función de vigilancia ha alcanzado a todos los ámbitos. En 
el caso de los servicios públicos, ésta nueva conducta del consumidor se ha convertido en una verdadera militancia, y no habrá indulgencia con las grandes organizaciones, públicas o privadas, que se escuden en las enormes estructuras organizativas.

Por tanto, la idea de que, en la Administración Pública, la eficacia y la eficiencia van de la mano parece perfectamente razonable. Se afirma que la prosperidad de un país en su totalidad depende del imperativo de servicio en el sector público y que no es sólo una exigencia para la empresa privada. Todos los países deben disponer de un sector público moderno, responsable y cualificado, capaz de ofrecer la ayuda necesaria. Cada vez parece más claro que la calidad y la eficacia de la Administración constituyen uno de los parámetros de la competitividad (Campanella y Corcovan, 1993).

En efecto, aunque el término calidad se encuentra cada vez más en boga entre gestores públicos y políticos, también constituye una importante fuente de confusión conceptual y cultural. Es más, se puede observar que hay muy poca literatura disponible en el entorno europeo sobre estudios basados en casos concretos de aplicación de estrategias de calidad en organizaciones públicas complejas. La experiencia de gestión de calidad del Instituto Nacional de la Seguridad Social (en adelante INSS) que se presenta, pretende responder a esa necesidad, de dar a conocer casos concretos. Esto requiere, además, la definición con claridad, precisión y respeto a las especificidades propias de cada Administración Pública, del marco de los cambios, su desarrollo, los conceptos básicos y las prácticas e iniciativas de gestión responsable a desarrollar.

Por otra parte, consideramos necesario llevar a cabo una valoración del camino emprendido por las Administraciones Públicas desde hace una década, ya que si las experiencias de calidad no se evalúan, no será posible su planificación, programación, garantía y consecución de objetivos equilibrados dentro del complejo marco organizativo tan característico de nuestros servicios públicos. Todo ello, sin perder de vista las consecuencias, tanto políticas como de índole organizativa, que conllevan los distintos enfoques conceptuales posibles acerca de la calidad.

Finalmente, el análisis de toda experiencia de reforma en torno al servicio del ciudadano y la búsqueda de la calidad en su relación de intercambio con las organizaciones públicas, sugiere llevar a cabo un balance prudente y matizado que huya de la retórica que no vaya acompanada de cambios profundos. Por tanto, se considera fundamental que, previamente al análisis de la experiencia concreta del INSS, se realicen un conjunto de precisiones conceptuales en torno a la aplicación de modelos de gestión de calidad en organizaciones públicas complejas. Todo ello desde la firme convicción de que el sector público necesita de una elaboración conceptual propia sobre la materia que nos ocupa (PÉrez MENAYO, 1996).

\section{Una década de estrategias de calidad: ise puede aprender de la experiencia?}

\section{Zapping managerial}

Las Administraciones Públicas de los países más desarrollados han experimentado en la última década un fuerte movimiento de transición hacia modelos de comportamiento que buscan un mayor equilibrio en las relaciones entre las organizaciones públicas proveedoras y los consumidores de servicios públicos. Así se ha incrementado la influencia de los usuarios en las prestaciones, mediante la ampliación de sus derechos de elección, información, participación, calidad del servicio y reclamación. Este movimiento fuerza a las Administraciones Públicas a renovar sus códigos de conducta y adopta el lenguaje de moda en el mundo empresarial. Esta búsqueda de nuevas formas de interacción con los ciudadanos-clientes abarca conceptos, prácticas, técnicas y métodos gerenciales importados del mundo empresarial: la Gestión de Calidad Total (GCT en adelante), el Marketing, son algunas de ellas. La calidad se ha convertido en un término fundamental de nuestra retórica contemporánea y ha influido los procesos de modernización y organización de los servicios públicos. Como enfatiza Poulit (1995), resulta difícilmente imaginable que alguien desee oponerse a la calidad, al igual que no parece posible oponerse a la virtud.

Ahora bien, la voluntad sentida entre muchos responsables públicos de construir una Nueva Gestión Pública independiente de las experiencias privadas requiere la comprensión de la insuficiente construcción conceptual en torno a los modelos de calidad aplicables. Asimismo, es necesario formular prudentemente preguntas fundamentales antes de lanzarse a adoptar a gran escala estas técnicas dentro de los servicios públicos. Sin perjuicio del análisis conceptual que se realiza más adelante, convenimos con SERIEYX (1991) que "transferir tal cual los instrumentos de management privado al universo de la Administración Pública es arriesgarse a desnaturalizar e incluso olvidar las finalidades específicas de la función públican.

En efecto, la imprecisión de los conceptos que subyacen alrededor de la modernización, la gestión pública de la calidad, la indefinición de objetivos y la confusión entre medios y fines han sido definidos por GIBERT y THÖENING (1993) como zapping managerial: la novedad prima sobre la continuidad, la personalización sobre la cultura colectiva, el consumo de modas manageriales se convierte en voluntarismo ingenuo y puede provocar el riesgo de banalización de los procesos de cambio. 


\section{Problemas singulares}

Desde la perspectiva de una década de implantación de estrategias de calidad en el marco global de la modernización, los autores citados más arriba realizan algunas valoraciones sobre el alcance de las reformas y los problemas singulares acaecidos en el sector público.

Esta visión objetiva, no exenta de cierto pesimismo (ver figura 4), requiere matizar que los responsables públicos tienen márgenes de actuación que pueden configurar un nuevo paradigma que ha de conjugar el interés público con el valor dado por los ciudadanos. Como señala el profesor MarTín MATEo (1994), los predicados de la gestión de calidad "son de aplicación al campo de los servicios públicos aunque con matizaciones y adaptaciones. Por mucho que lo intentemos, la Administración no puede equipararse sin más a las organizaciones privadas, lo que la privaría de las características que han propiciado su existencia (...) Es por tanto un sin sentido, sólo propio de la inmadurez de ciertas disciplinas sociales, el descalificar el modelo normativo, que no es otro que el derivado de los imperativos del Estado de Derecho (...). Pero una cosa es que respetemos de buena gana el principio del imperio de la ley (...) y otra aceptar de buen grado que un denso entramado reglamentario deba sustituir la creativa iniciativa de los componentes de las organizaciones públicas".

\section{Equilibrio entre entidades proveedoras públicas y ciudadanos: desafíos}

En la Europa continental uno de los intereses primordiales de las Administraciones Públicas se centra en la norma jurídica y la situación en que se encuentra el ciudadano frente a ella. Por tanto, el respeto a la legalidad y a la protección del ciudadano tienen una importancia mayor que la nueva exigencia de calidad en un producto o servicio (Polut y BOUCKAERT, 1995). No obstante, se trataría de encontrar el necesario equilibrio de las obligaciones entre las organizaciones proveedoras del Estado y los ciudadanos, que conllevaría algunos desafíos:

- Aceptación del cambio de valores y de actitudes por parte de los ciudadanos (la aimagen negativa espontánea" ante todo lo público) y de los empleados públicos (la presunción de que conocen las expectativas de los usuarios y, por ende, definen el interés público).

- Aceptación de los cambios necesarios en la estructura administrativa, ligados a la gestión de calidad, por la alta dirección política y los directivos públicos.

- Toma de conciencia del papel de la gestión de calidad como fuerza motriz para ayudar a los responsables pú-

\begin{tabular}{|c|}
\hline 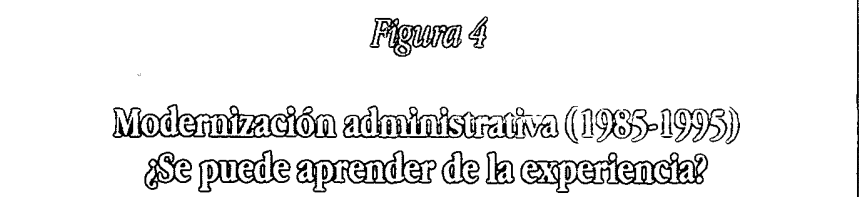 \\
\hline $\begin{array}{l}\text { ZAPPING MANAGERIAL: } \\
\text { Indefinición de objetivos e imprecisión de conceptos. } \\
\text { Inquietud de los empleados públicos ante las oleadas de reformas sucesivas en un } \\
\text { contexto de reducción de efectivos. }\end{array}$ \\
\hline $\begin{array}{l}\text { Cuestionamiento de atribuciones de los órganos centrales de la Administración. } \\
\text { Falta de credibilidad de los resultados de la modemización para indicar una } \\
\text { dirección clave a seguir. }\end{array}$ \\
\hline $\begin{array}{l}\text { Frivolidad de lanzar proyectos sin diseño ni compromiso claro de los directivos, } \\
\text { transfiriendo la carga a los escalones inferiores de la organización. } \\
\text { El control de la gestión y la adhesión de los funcionarios no marchan en la misma } \\
\text { dirección y los proyectos se manifiestan vacíos y triviales. }\end{array}$ \\
\hline $\begin{array}{l}\text { Sucesión de etiquetas y eslóganes fundados más en la personalización de la política } \\
\text { que en el cambio de cultura colectiva. } \\
\text { La modemización se convierte en fruto de la arbitrariedad del último } \\
\text { nombramiento, sus protegidos y los "gurús" del momento (ausencia de } \\
\text { continuidad). }\end{array}$ \\
\hline $\begin{array}{l}\text { En definitiva, la Administración adolece de un déficit en la elaboración conceptual } \\
\text { de la modernización y de una incapacidad de modificación de conductas de } \\
\text { aprendizaje en principios y prácticas manageriales. }\end{array}$ \\
\hline
\end{tabular}

Fuente: Elaboración propia y GILBERT y THÖENING (1993).

blicos a transformar las organizaciones en modernos Sistemas de Servicios.

\section{Propuestas previas}

Pecaríamos de falta de rigor si pensáramos que la transformación de las relaciones entre las Administraciones Públicas y el ciudadano han pasado, después de una década de modernización, del modelo de dominación burocrática de pasividad, dependencia y sumisión, a otro modelo centrado en el cliente, considerado accionista, consumidor y ciudadano (GYFORD, 1991).

En primer lugar, esta transición según muchos expertos tiene sus limitaciones en la especificidad del sector público, más complejo en sus modelos de relación, en la dimensión colectiva relacional y en el nivel macro de diseño de objetivos y políticas, y la participación de los ciudadanos. En este nuevo marco de relaciones de servucción (SERVicios + prodUCCIÓN: producción de servicios) todos los expertos señalan como una de las cuestiones previas ser consciente de que las soluciones instrumentales son atrayentes en su apariencia pero poco eficaces si no se integran en una reflexión estratégica de toda la organiza- 
ción que produzca un compromiso entre el discurso y la acción. Las soluciones instrumentales ofrecen respuestas simples y directas con el riesgo de ser inadaptadas, incomprendidas y mal utilizadas. Este planteamiento corresponde al marketing de primera generación (HERMEL y ROMAGNI, 1990), como marco de actuación en el ámbito público. Se caracteriza porque los servicios son poco o mal conocidos y utilizados, ante lo cual se orienta la solución hacia la comunicación, mediante publicidad y promoción del servicio en los puntos de contacto con el público, y a la resolución de los problemas de acogida, donde se crean puntos de información y servicios de reclamaciones.

En efecto, la mayoría de las administraciones occidentales han dedicado considerables esfuerzos en los últimos años a la mejora de las condiciones en las que tiene lugar la relación entre los ciudadanos y los poderes públicos. Se trata de estrategias orientadas al punto de encuentro, en el que se efectúan las transacciones y están dirigidas a los distintos elementos que intervienen en el mismo: espacio físico, personal, organización, procedimientos, información, comunicaciónin, participación, etc. (LCHEvarría, 1993) - ver figuras 5 y 6-. Pero, como se puede apreciar en los estudios de la Unión Europea y la OCDE, se trata de una aproximación al ciudadano muy reducida, al limitarse básicamente al contacto externo entre él y la Administración, sin incluir una dimensión de contenido político o del proceso de toma de decisiones compartido. Este tipo de Administración amables puede quedar reducido a una simple caricatura o llegar incluso a irritar al ciudadano por realizarse defectuosamente y con poca precisión, o por tardar más de lo que es necesario a causa de los conocidos procedimientos burocráticos (RÖBER, 1989). Pero aunque no se produzca una auténtica renovación organizativa, se facilita la entrada de la calidad en las instituciones públicas.

\section{Iferances 5}

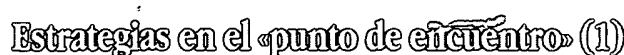

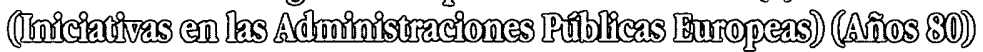

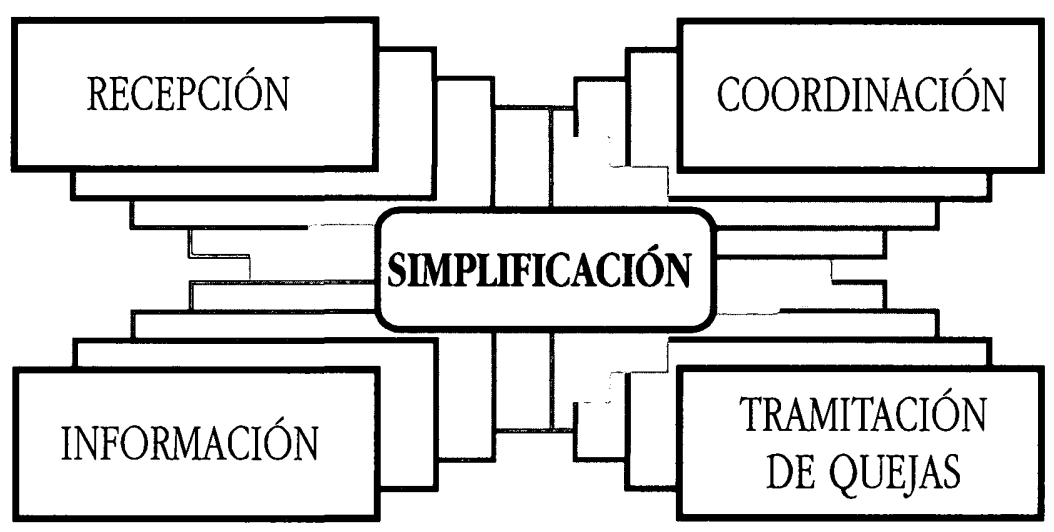

En segundo lugar, ninguna reforma profunda de la acción del Estado puede tener éxito sin la participación activa de los actores (ciudadanos y empleados públicos). Lo que está en juego es la capacidad de iniciativa de las personas. Si no se revaloriza el conocimiento de los funcionarios no se pueden producir resultados profundos y duraderos. La participación para ser útil debe efectuarse en un marco metodológico serio y con respeto a los principios éticos profesionales. El interés del cambio y sus límites deberían ser claramente delimitados desde el comienzo. La ambigüedad sobre el alcance de las reformas, la incertidumbre, los términos vagos, no pueden conducir a un proceso de avance concreto. Es preciso evitar juicios globales que pueden desvalorizar a los funcionarios sobre generalizaciones no significativas acerca de la ineficacia del Estado, o la insatisfacción de los clientes.
Por último, es prioritario definir y difundir metodologías apropiadas que traten sobre las técnicas de calidad total, los comportamientos de cambio en las organizaciones, la formación con un alto contenido técnico pero también relacional y centrada en necesidades. Las estructuras existentes y diferenciadas del sector público, tanto centrales como periféricas, parecen poco adecuadas para los retos y demasiado aisladas por relación a los que producen las ideas y los métodos. Los directivos deberían profesionalizarse en temas de calidad y cambio organizativo para organizar y difundir los conceptos, los métodos, las prácticas y el intercambio de experiencias en materia de Dirección y Gestión de Calidad (Barouch, 1994) - ver figura 7-. 


\section{Fisoura (6)}

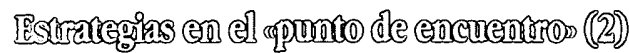

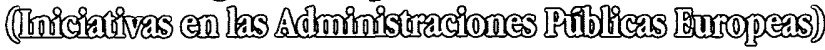

SIMPLIFICACIÓN DEL DERECHO (un *camino más corto*) con tendencias a la desregulación.

SIMPLIFICACIÓN DEL LENGUAJE de las leyes, reglamentos y formularios utilizados por las organizaciones públicas con la aspiración de facilitar al ciudadano la lectura y comprensión de las normas.

MAYOR ACERCAMIENTO DE LAS ORGANZZACIONES PÚBLICAS al ciudadano mediante la descentralización de las oficinas, creación de un entorno amigable", formación relacional de sus empleados y adaptación horaria a las necesidades de los ciudadanos.

Introducción de NUEVAS TECNOLOGÍAS de información para aumentar la RAPIDEZ Y FLABILIDAD de los datos y la calidad de la producción.

INNOVACIONES en la organización de las OFICINAS DE ATENCIÓN: cualquier empleado público debe resolver cualquier solicitud del ciudadano sin que se vea obligado a buscar un especialista.

Atender a la PROMOCIÓN DEL PERSONAL: pocos avances aunque parece razonable predecirlos para un futuro.

Introducción de HERRAMIENTAS DE CONTROL: •medición de rendimientos. versus asólo procedimientos juŕdicos destinados a controlar la observación de las prescripciones normativas.

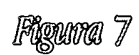

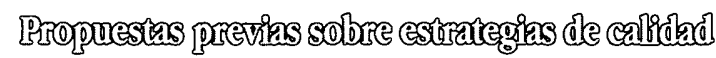

Integración en una reflexión estratégica de toda la organización que produzca un compromiso entre el discurso y la acción.

Ninguna reforma profunda de las Organizaciones Públicas puẹde tener éxito $\sin l a$ participación activa de los actores. empleados públicos y clientes.

Prioridad en metodologias apropiadas y necesaria construcción conceptual en tomo a los modelos de calidad aplicables.

Rol de los directivos: necesaria profesionalización emanagerial. (enfoque de habilidades de integración organizativa y de personas y formación específica en Gestión de Calidad Total $\rightarrow$ cero desprecios - .

Alternativas: "modelo incubadora. 0 •modelo de innovación aguda.

\section{De la calidad "ortodoxa" a la calidad ureformada"}

Durante la última década, la Gestión de la Calidad Total (GCT) ha tenido un gran impacto sobre las prácticas gerenciales y ha sido adoptada por grandes corporaciones privadas, y ha comenzado a ser objeto de atención en muchas organizaciones públicas en los países más desarrollados. Así, los principios de mejora de la calidad se refieren tanto al sector público como a las organizaciones con ánimo de lucro. Aprobaciones tan entusiastas a menudo sugieren que la GCT puede ser transferida del sector privado al público con muy pocas modificaciones. Nada más lejos de la realidad. La GCT puede jugar un papel en la Administración, pero sólo si se modifica sustancialmente para ajustarse a las características peculiares del sector público (PÉREZ MENAYO, 1996) -ver figura 8-.

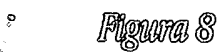

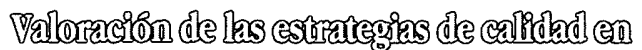

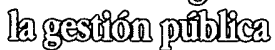

Fracasos por uso de la estrategia de calidad como herramienta para aborro de costes y aumento de la eficacia.

Falta de estructura formal y el compromiso de todos los niveles necesarios para que funcione la estrategia de calidad.

Debilidad de los programas de formación antes de establecer sistemas de apoyo de la estrategia de calidad.

Aplicación de soluciones a los sintomas y no a la raíz de los problemas.

Iniciar proyectos de alcance imposible a los equipos de calidad.

La Gestión de la Calidad Total es un sistema compuesto por un conjunto de conceptos, métodos y herramientas, que permite alcanzar unos determinados estándares de calidad en un proceso de mejora continua. Supone, además, un cambio en todos los niveles organizativos mediante el perfeccionamiento de cualquier aspecto técnico o administrativo que se considere susceptible de mejora. La CGT pretende la integración de todos los procesos y procedimientos de las áreas funcionales así como implicar a todo el personal involucrado con el apoyo de la Organización. Asimismo, la GCT se basa fundamentalmente en el factor humano, es decir, en el compromiso firme y activo de todos los empleados en el objetivo de la calidad. Nada de lo expuesto puede ser ajeno al ámbito público, o más bien constituye una exigencia tanto de los ciudadanos como del propio personal al servicio de la Administración Pública.

A continuación vamos a realizar un conjunto de precisiones que consideramos necesarias para convertir la GCT ortodoxa (en acepción de SwISS, 1992), en una GCT reformada con posibilidades de aplicación al ámbito público. En primer lugar, la GCT exige un aggiomamento para su uso en el ámbito público porque, en su concepción original, fue una técnica gerencial de control estadístico y de aplicación en el sector industrial. 
Entre las diversas definiciones dadas por los apadres de la GCT a la calidad, retenemos la ofrecida por DEMING (1989): calidad es la satisfacción plena de la sociedad. Aunque la estrategia de la GCT basada en Deming no es el único sistema de calidad existente (Crosby, 1987; JuRán, 1990; Peters, 1989), su versión desde una perspectiva totalizadora de satisfacción social, es con mucho la más influyente y extendida. Como DEMing es un sintetizador la GCT contiene muchos de los conceptos de otros sistemas de management de calidad. La estrategia de la GCT es un sistema complejo y exigente que no puede resumirse en unos pocos párrafos. Sin embargo, podemos sintetizar sus pautas más importantes en siete principios básicos (ver figura 9).

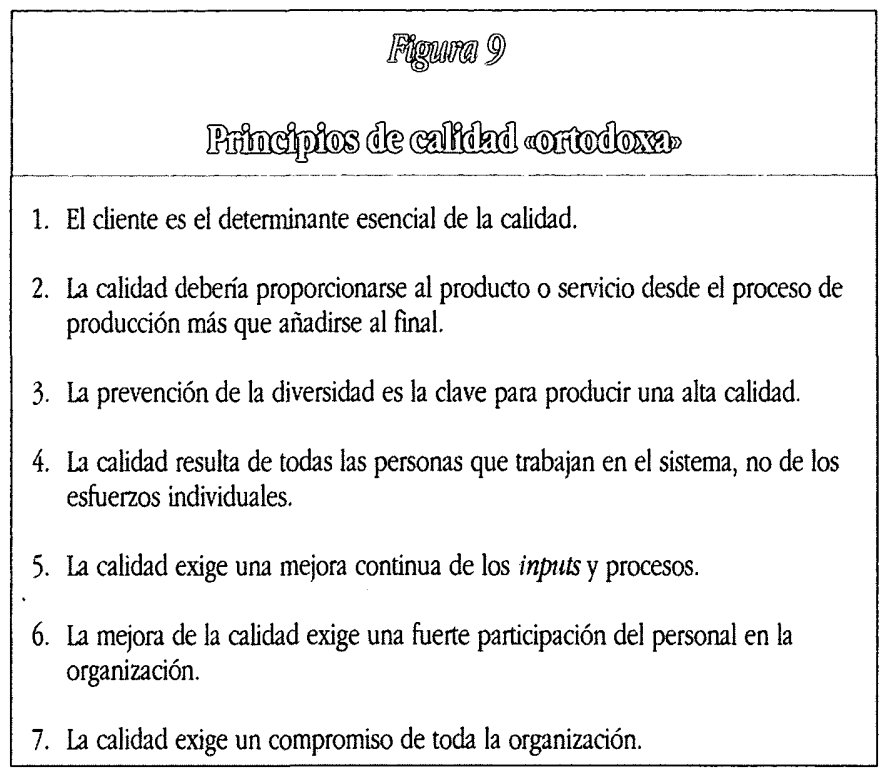

La calidad, por tanto, se convierte en un enfoque sistémico: abarca todas las actividades de la organización; el compromiso de cada miembro de la misma; cada persona como proveedor y cliente interno o externo de otras personas; la búsqueda de la participación y el compromiso de todos. Además, tiene como objetivo final obtener la satisfacción de todos los miembros de la organización con su trabajo, que implica mejoramiento continuo que involucra a todos, directivos y empleados públicos por igual (IMAI, 1989).

Llegados a este punto de la exposición, cabe preguntarse de nuevo con el profesor MarTín MATEO (1994), "si la estrategia de la calidad total puede ser asumida, sustancialmente por la Administración Pública y, en particular, por las Administraciones de más reducido espectro servicial. En principio detectamos en estos ámbitos grandes dificultades tanto estatutarias como sociológicas para que pueda prender la cultura de la calidadn, dado el componente coercitivo y punitivo de algunas actividades de la función pública (servicios de ordenación social -ver más adelante-) - ver figura 10 -

Debilidad en la elaboración conceptual (calidad, Gestión de Calidad Total (GCT),
circulos de calidad, equipos de progreso, ...): ambigüedad sobre el alcance, la
incertidumbre, los términos vagos, las modas, ...
Dificultad para definir el cliente de las Administraciones Públicas.
Enfasis excesio en los recursas y procedimientos. presupuestos, control de personal,
estrictas nomas, ...
Cultura administrativa, basada en el paradigma burocrático y abierta a fuerzas
externas.
La aplicación de estrategias de calidad requiere una cultura fuerte con un
compromiso de calidad.
Las Administraciones Públicas han de pasar de estar centradas en si mismas
(paradigma burocrático) a ser abiertas y sensibles a las necesidades del
cindadano-cliente (paradigma emergente).

Por su parte, SwISS (1992) se interroga: ¿Es útil el Total Quality Management para las organizaciones del sector público? Este autor argumenta que la forma ortodoxa de la GCT expresada en los trabajos de Deming, y otros, no va a funcionar bien en las agencias gubernamentales por varias razones. Entre otros factores que limitan la aplicación de la GCT ortodoxa se encuentra el énfasis sobre los productos en lugar de sobre los servicios, sobre los grupos de consumidores bien definidos, sobre inputs y procesos más que en resultados, y sobre una cultura organizativa con una única preocupación por la calidad. Swiss preconiza una Gestión de la Calidad Total reformada que deseche la hostilidad de la GCT ortodoxa hacia los objetivos y medidas de los resultados, incorporándolos, que no enfatiza la demanda de uniformidad de los resultados y de la cultura organizativa, y sensibiliza a los directivos frente a los peligros de satisfacer sólo a una clientela inmediata. Al mismo tiempo la GCT reformada salva los principios ortodoxos de delegación al personal, la mejora continua y el seguimiento cuantitativo de la trayectoria de la calidad del producto o servicio y de las percepciones de los clientes. Finalmente, si se logra introducir la Gestión de la Calidad Total sin excesiva propaganda y con sensibilidad hacia los valores y actitudes que conforman la cultura administrativa pública, la GCT reformada, adecuadamente implementada, puede contribuir eficazmente a la gerencia pública contemporánea (ver figura 11). 


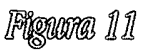

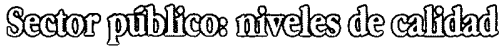

\section{MICROCALIDAD}

CALIDAD INTERNA referida a las relaciones entre las esferas superior, media e inferior de una organización. PRESUPUESTO BÁSICO: una plantilla satisfecha y comprometida trabaja de manera más efectiva.

\section{Posible distorsión ideológica}

Exigir un -COMPROMISO", "ACTITUDES" O SIMPLE OBEDIENCIA, hace que resuenen incómodamente los ecos del Gran Hermano (ORwell, 1949).

\section{MESOCALIDAD}

CALIDAD EXTERNA del servicio aplicable a las relaciones entre proveedores y consumidores, con especial atención a estos últimos.

PRESUPUESTO BÁSICO: armonía de intereses entre proveedores del servicio y el público.

Posible distorsión ideológica

Abuso del PRINCIPIO DE PARTICIPACIÓN del consumidor que pueda permitir la MANIPULACIÓN del usuario por tecnócratas o profesionales.

\section{MACROCALIDAD}

Concepto genérico referido a la RELACIÓN entre un SERVICIO PÚBLICO y la CIUDADANÍA y entre el ESTADO y la SOCIEDAD CIVIL. La mejora de la calidad provocará la LEGITIMIDAD de un determinado Sistema de Gobierno.

\section{Posible distorsión ideológica}

Los intentos sousseaunianos de renovación de los compromisos sociales entre gobemantes y gobernadores a través de las "CARTAS DE LOS CIUDADANOS", pueden utilizarse para crear una publicidad favorable $\mathrm{e}$ incrementar el CONTROL CENTRALIZADO DEL ESTADO SOBRE LOS ESTÁNDARES DE CALIDAD

Fuente: Elaboración propia y POLLIT y BOUCKAERT (1995).

Otro aspecto, nada desechable, se refiere a la cultura organizativa. SERIEYX (1991), afirma: "la Administración, totalmente encorsetada por la multiplicidad de cuerpos y la rigidez del estatuto de la función pública, es por naturaleza poco apta para poner en práctica procesos de calidad total. En efecto, tales procesos exigen relaciones internas fluidas, un funcionamiento transversal, relaciones "cliente-proveedor" instauradas entre todos los actores, todos los servicios, todas las direcciones, todas las administraciones...; en resumen, exactamente lo contrario de lo que preside al espíritu de cuerpo, de escalafón, de territorio. Por su estructura interna, cada Administración tiene tendencia a estar en primer lugar al servicio de sí misma, y cada dirección o subdirección existente a caer en su seno en el mismo tropismo".

\section{Paradojas de las organizaciones públicas}

\section{Relaciones de intercambio: diferencias entre los sectores privado y público}

En el sector privado las relaciones de intercambio de información en el mercado entre productores y clientes son muy directas y recuerdan constantemente al productor la importancia de responder a los deseos del consumidor (libre elección individual en el mercado). En el ámbito público, el nexo individual de intercambio se relaja o desaparece por completo; sólo los grupos continuarán firmemente vinculados (elección colectiva de la política). Como señala JASAY (1988), para un conjunto de individuos, ciudad o nación, las cotizaciones totales corresponden a las prestaciones totales (p.e. el principio de caja única en el sistema español de protección social responde a este axioma). Sólo por casualidad las cotizaciones de una persona coinciden justamente con las prestaciones que se reciben, pero tampoco se pretende que así sea (ver figura 12).
Por otra parte, en el sector público la retroalimentación referida a la calidad del servicio tiene una fuerza menor: gratuidad o importe subsidiado por los impuestos; restricción o limitación de la demanda con una reducción escasa o nula del presupuesto; o incremento de la demanda y/o la presión social sin elevación del presupuesto. La posición de monopolio u oligopolio del proveedor público requiere tener en cuenta que si un cliente se siente insatisfecho con el servicio no puede acudir a otra organización en las mismas condiciones. La ausencia de competitividad en el mercado en gran número de áreas del Sector Público puede restringir el desarrollo de expectativas. Por otra parte, puede hacer desaparecer la motivación de los proveedores públicos para averiguar las expectativas de sus clientes, puesto que éstos no disponen de la posibilidad real de optar por otros servicios. Por tanto, no parece sorprendente que parte del monopolio o semimonopolio de los servicios públicos hayan evolucionado siguiendo una tendencia del dominio de los proveedores públicos y no de los usuarios (ver figura 13).

Como señala BARZELAY (1992), «el propósito de las reformas burocráticas ha sido servir al interés público. La Administración debería servir al interés público, argumentaban los reformistas, si es honesta y eficiente. Por honesta querían decir una Administración sin particularismos, subvenciones excesivas y sin apropiación de fondos públicos. Por eficiente, querían decir una Administración que mejorara las infraestructuras, proporcionara educación, salud, ..., en definitiva los denominados servicios esenciales. La estrategia de los reformistas de servir al interés público les llevó a definir el interés público. Esta estrategia fue diseñada no sólo para alcanzar resultados (eficacia) sino para legitimar las acciones de los funcionarios. Como consecuencia, estos funcionarios llegaron a presumir que siempre se servía al interés público. Esta presunción ya no es razonable. La Administración a menudo no logra los resultados deseados des- 


\section{5iongra 128}

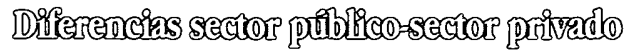

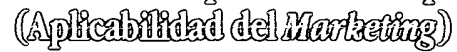

\section{MODELO DEL SECTOR PRIVADO}

- Libre elección individual en el mercado.

- Precio y demanda.

- Equidad del mercado.

- Búsqueda satisfacción del mercado.

- Soberanía del cliente.

- La competitivad como instrumento de mercado

- La ssalida del producto como estímulo.

\section{MODELO DEL SECTOR PÚBLICO}

- Elección colectiva de la política.

- Necesidad de recursos.

- Igualdad en la necesidad.

- Apertura para la acción pública.

- Ciudadanía.

- La búsqueda de la justicia.

- Acción colectiva como instrumento de la política.

- La opinión como condición. de el punto de vista de los ciudadanos cuando cada colectivo profesional de la Administración piensa que sus estándares definen el interés público. Para estimular el debate sobre cómo el trabajo de la Administración tiene que ver con las necesidades de los ciudadanos, el paradigma post-burocrático sugiere que la expresión retórica interés público debería quedar confinada a los libros de historia de la Ciencia Política y de la Administración. Esta expresión puede usarse para motivar una mayor argumentación y deliberación más productiva sobre lo que los ciudadanos valoran.

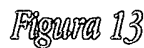

\section{Paractolas ex el sector putblico}

La calidad no deriva automáticamente de consideraciones de una sola dimensión (p.e. si los usuarios están satisfechos, la calidad es buena), sino que más bien consiste en una *selección* entre diferentes criterios:

$\Rightarrow$ Expectativas del ciudadano-cliente, establecimientos de normas contando con la experiencia de los profesionales.

$\Rightarrow$ Restricciones de gasto y objetivos específicos del sector público.

La paradoja actual del sector püblico es que necesita buscar la satisfacción del usuario y al mismo tiempo ser consciente del hecho de que éste no es el único criterio relevante.

Hay que evitar, dos posiciones principales:

$\Rightarrow$ Basar la acción de la función pública exclusivamente en términos de la satisfacción del usuario.

$\Rightarrow$ A la inversa, permitir que los funcionarios públicos continúen pensando que tienen un conocimiento espontáneo e interno de las expectativas de sus clientes.

La función püblica insiste en que en sus decisiones tiene en cuenta el punto de vista de los ciudadanos.
La Administración Pública tradicional, como señala CROzIER (1974), funciona como un sistema estable con unos principios que condicionan un estilo y unas capacidades. El primero de ellos es una tendencia irrefrenable a la impersonalidad tanto en su acción como en sus estructuras y mecanismos de decisión. Este mismo mecanismo funciona en las relaciones de la Administración con la sociedad que se caracterizan, sobre todo, por el sindrome de evitarse. Los ciudadanos de una parte están condenados a lo impersonal y lo uniforme, sin interlocutores accesibles; los funcionarios, de otra, constreñidos por el cumplimiento de normas y trámites, sin margen de maniobra para la comprensión de situaciones individuales. A este distanciamiento o bloqueo corresponden disposiciones legales o reglamentarias que crean cauces formales para la participación de ciudadanos y grupos en algunos procedimientos (p.e. sistemas de participación de los interlocutores sociales en la Administración Social; asociaciones que vertebran a los clientes de las organizaciones públicas ...).

Conviene precisar con TROSA (1995) que la calidad en las organizaciones públicas no puede derivar automáticamente de consideraciones de una sola dimensión, sino que más bien consiste en una selección entre diferentes criterios: las expectativas y objetivos legítimos del ciudadano-cliente, y el establecimiento de normas y objetivos específicos del Sector Público, teniendo en cuenta los escenarios de austeridad del gasto y contando con la experiencia de los profesionales de la función pública. La paradoja actual de las Administraciones Públicas es que necesitan buscar la satisfacción del ciudadano y al mismo tiempo tener conciencia de que éste no es el único criterio relevante. Conviene evitar dos posiciones principales: 
- Basar la acción de la función pública exclusivamente en términos de la satisfacción del usuario-cliente.

- Y a la inversa, permitir que los funcionarios públicos continúen pensando que tienen un conocimiento espontáneo e interno de las expectativas de los ciudadanos.

Como puntualiza Polut (1995), la función de los gobiernos desdibuja la distinción entre proveedor (Administraciones Públicas) y ciudadano, ya que representan a ambos; esta dualidad da lugar en ocasiones a un comportamiento "esquizofrénico" por parte de los gobiernos:

- Por una parte, se procurará definir con gran exactitud el nivel máximo de lo que se ofrece (calidad del proveedor), con el objeto de modular las expectativas del público y conseguir un ahorro (complaciendo así a los contribuyentes y al entorno económico-financiero).
- Por otra, presionarán a los facilitadores del servicio público para que sean más receptivos hacia los usuarios con el objeto de complacer a los clientes electores y así acrecentar la legitimidad política.

Finalmente, esta dualidad paradójica entre, por un lado, la calidad entendida desde la perspectiva del proveedor (paradigma burocrático) y, por otro, la calidad entendida desde la óptica de los ciudadanos (paradigma del cliente), requiere, para las Administraciones Públicas, un híbrido de las dos estrategias que incremente la legitimidad de la autoridad proveedora (ver figura 14). Para ello, conviene evitar promover medidas solamente superficiales a corto plazo (folletos "brillantes", oficinas "elegantes"...) para intentar convencer al público de que el servicio está mejorando ya que, como sucede a veces, es más fácil maquillar el escaparate que hacer reformas profundas (ver figura 15).

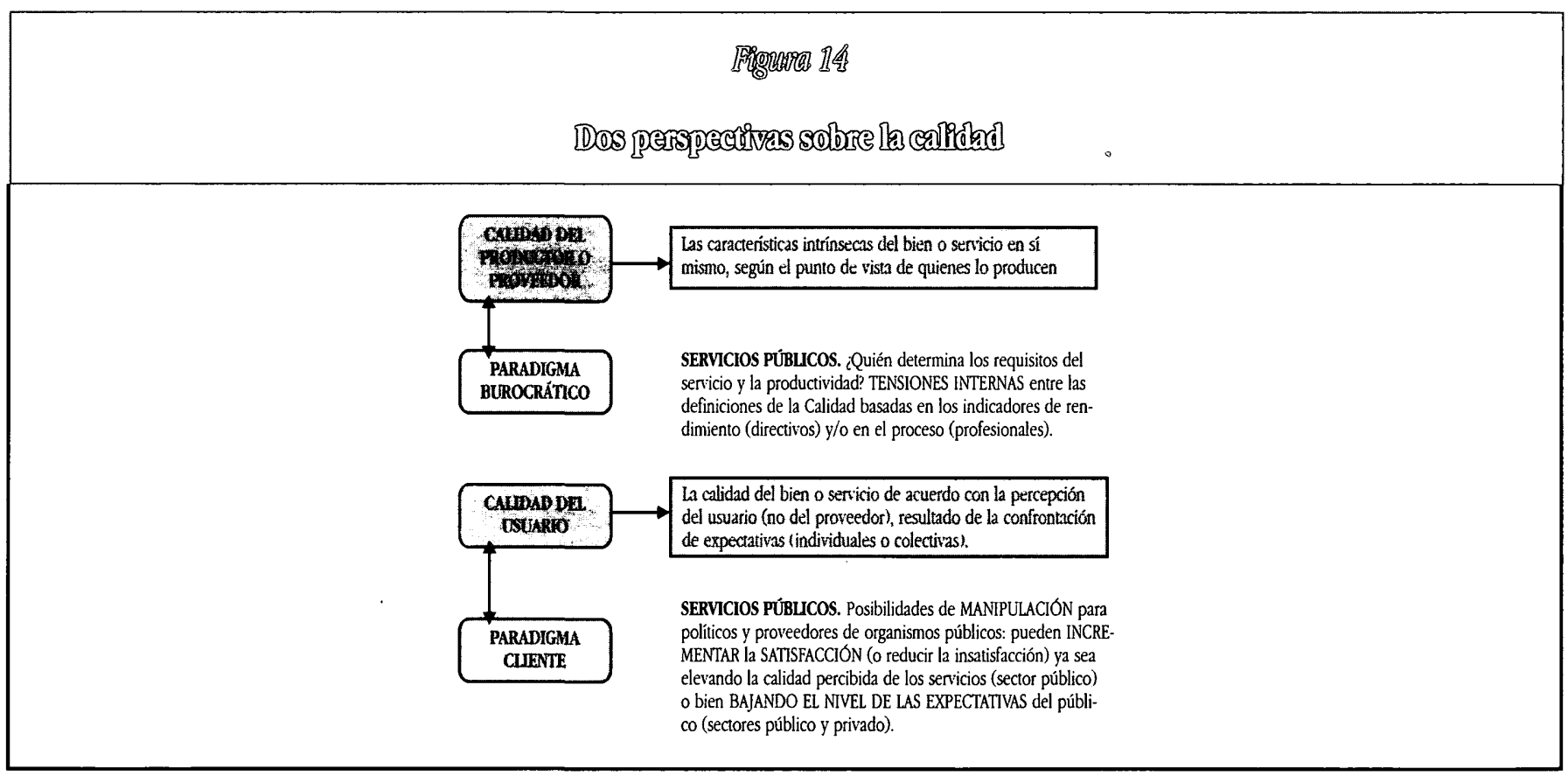

\section{Servicios de «Ordenación Social» versus Servicios de "Necesidad Social"}

El enfoque básico de la GCT que discurre alrededor de la idea de que el consumidor o cliente final se convierte, no sólo en el destinatario último que paga el servicio y es su razón de ser, sino en juez del rendimiento de quienes prestan el servicio ha llevado a algunos autores a señalar que la GCT no puede ser un planteamiento determinante de la forma en que se gestionan los servicios públicos. Un componente importante de la función pública es de tipo coercitivo: asegurar el cumplimiento de las disposiciones legales, aun cuando ello se deba hacer contra la voluntad del "cliente", que puede tratarse en algunos casos, de un delincuente o de un defraudador. Efectivamente, cuando las Administraciones ejercen la autoridad punitiva que le reservan las normas jurídicas, la percepción del "servicio" por parte del "cliente" puede verse seriamente afectada.

En efecto, algunos servicios públicos se facilitan en contra de los deseos del usuario directo; forman parte del mecanismo del control del Estado: instituciones penitenciarias y cuerpos de seguridad; sistemas de inspección (medio ambiente, trabajo y seguridad social; tributos...). Son los denominados servicios de ordenación social (STEWART, 1992). Por tanto, basar los estándares de calidad de estos servicios en la opinión de los delincuentes, contaminadores o defraudadores..., resulta obviamente ilógico. Determinar cuáles son los estándares de calidad aceptables re- 


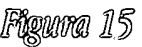

Estrategians de calldards categrorias

\section{CALIDAD DEL PRODLCTOR}

$\Rightarrow$ Se supone que el PROVEEDOR SABE LO QUE ES LA CALIDAD.

$\Rightarrow$ Instalación de SISTEMAS DE CONTROL. Los usuarios o los consumidores finales del producto o servicio pueden beneficiarse de estos esfuerzos de control, pero no forman parte de ellos.

EN EL SECTOR PÚBLICO SE ASOCIA A CONTROL DE COSTES E INCREMENTO DE LA PRODUCTIVIDAD DE LOS SERVICIOS.

\section{SATTSFACCIÓN DEL CLIENTE}

$\Rightarrow$ Sólo LOS USUARIOS PUEDEN DECIR AL PRODUCTOR/PROVEEDOR CUALES SON LAS CARACTERÍSTICAS DEL SERVICIO QUE VALORAN en mayor medida y cual debería ser el OBJETTVO DE LOS ESFUERZOS en relación con la fijación y la evaluación de los estándares de calidad.

AUMENTAR LA LEGITIMIDAD DE LA AUTORIDAD PROVEEDORA

(Hibrido de las dos anteriores)

$\Rightarrow$ La dirección política promueve MEDIDAS SUPERFICIALES A CORTO PLAZO (folletos brillantes, oficinas elegantes, ...) para convencer al público de que el servicio está mejorando.

$\Rightarrow$ La búsqueda de la LEGITIMIDAD DEMOCRÁTTCA no es sólo un ejercicio de relaciones públicas.

$\Rightarrow$ Conservar la CONFIANZA DE LOS CIUDADANOS y la popularidad de los Servicios Públicos básicos pasa por emprender ESFUERZOS SERIOS a largo plazo destinados a MEJORAR LA CALIDAD.

sulta mucho más complicado que lo que se puede plantear en el sector privado.

Ello no debe ser, sin embargo, ninguna excusa para que cada Administración se esfuerce en identificar y conocer las expectativas y requisitos que sus clientes demandan del servicio y cumplir o superar esas demandas. La función de los diferentes órganos de la Administración, una vez que las normas están en vigor, consiste en posibilitar el ejercicio de los deberes contemplados en esas normas por parte de sus clientes, en satisfacer sus expectativas y facilitar el ejercicio de sus derechos cuando se tengan que poner en contacto con dichos organismos. El ciudadano-cliente todavía demanda de este tipo de servicios públicos el ser tratado con corrección, rapidez y el mínimo de incomodidad. No hay ninguna contradicción en el hecho de que pueda llegar a estar satisfecho con el servicio que recibe, aunque su contrapartida tributaria o de cotizaciones sociales no le parezca la más adecuada (LOPEZ MaRTínEZ, 1993).

Determinados servicios públicos (sanidad, seguridad social, enseñanza...) se derivan más de los propósitos colectivos, de las competencias de los organismos o de las funciones de los profesionales, que de los deseos del consumidor; servicios de provisión directa en donde el usuario potencial no puede expresar sus deseos de forma efectiva (mayores, enfermos, generaciones futuras...). Son los denominados servicios de necesidad social ( $\mathrm{p}$. e., el Instituto Nacional de la Seguridad Social).

Por tanto, la calidad del servicio en las organizaciones públicas necesita de una colaboración entre el proveedor y el usuario; en muchos casos, además, es difícil estandarizar por adelantado la calidad del servicio ya que requiere de la discrecionalidad de los profesionales que lo prestan.

\section{Ciudadano y/o cliente: ¿de quién estamos bablando?}

Usuario, ciudadano, contribuyente, consumidor, cliente.... Todos estos términos son utilizados indistintamente para definir el público objetivo en las organizaciones públicas y existe un debate interminable en torno al significado de cada uno de ellos en la, hasta ahora, breve historia de la Gestión de Calidad en el sector público. El Estado liberal conllevó la idealización del concepto de ciudadano como aquél dotado de una total plenitud de derechos y capacidades. Por tanto, en el ciudadano se concentran derechos y obligaciones en una persona física dentro de un Estado de Derecho y sujeto a una jerarquía normativa. En el cliente se concentran un conjunto de necesidades y de satisfacción de las mismas en una persona en un contexto de un mercado sujeto a la oferta y la demanda de bienes y servicios, formando parte de una jerarquía de necesidades que dependen del deseo de retribuirlas (SuBIRATS, 1990).

No obstante, el término cliente hoy parece abrirse paso como nuevo concepto interpretativo de las relaciones entre individuo y Administración Pública. Con éste se pretende reforzar una relación que configura el Estado como una fuente de protección y servicios (Estado de Bienestar), pero poco propicio a diferenciaciones previamente estandarizadas (OCDE, 1987). La condición de cliente de los ciudadanos se entiende como manifestación de mayor exigencia, de mayor activismo por ambas partes (Administración y cliente), e incorpora no solamente personas sino, además, empresas, grupos, asociaciones ... Algunos autores son más críticos con el término cuando afirman que conceptualizar a las personas, en su trato con el servicio público, como clientes, es suponer una relación a un tiempo inexacta y errónea. Para empezar, considerar a las personas como clientes es fomentar una visión del servicio público como un supermercado (WINKLER, 1987; HOOD y WRIGHT, 1981). En definitiva, el ciudadano es parte de un contrato social, mientras que el cliente forma parte de un contrato de mercado (ver figura 16).

Por su parte, la Comunidad Europea (hoy U.E.) (1991), propone la utilización del término consumidor, más neutral. Esto conlleva la definición del término protección del consumidor como la adopción de una filosofía orientada al consumidor y la incorporación de una serie de medidas prácticas que aumenten la sensibilidad de los servicios públicos respecto a la influencia del consumidor. No obstante, tampoco el término consumidor se considera pacífico, ya que el énfasis sobre el consumo fomenta el desarrollo de las que denominamos más atrás "Políticas de Apetito Nacional Bruto" - FarLIE (1968) - (p.e. la media 
Fifongersa 116

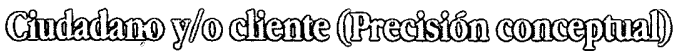

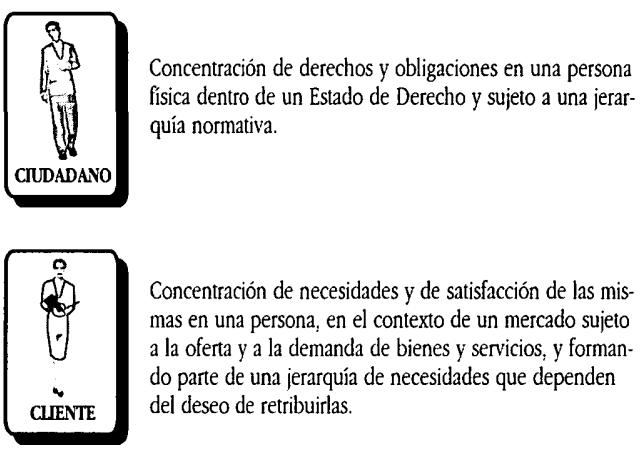

EL CIUDADANO ES PARTE DE UN CONTRATO SOCIAL, MIENTRAS QUE EL CLIENTE FORMA PARTE DE UN CONTRATO DE MERCADO.

del Gasto en Protección Social respecto al PIB en la Unión Europea se encuentra en torno al 27 por 100; para España, 23,6 por 100 -EUR12; metodología SEEPROS; Eurostat-).

Ahora bien, un consumidor no es necesariamente un ciudadano: no tiene el sentimiento de pertenencia a una comunidad ni adquiere responsabilidad por sus actos; no le mueven motivos de altruismo o de solidaridad, sino estrictamente egoístas. Pero nadie puede ser ciudadano hoy en día si no ejerce sus derechos como consumidor. Si en su condición de tal aumenta su posibilidad de elegir (mercado directo, comercio electrónico) está mejorando su nivel de vida y, por tanto, sus derechos políticos también se ven potenciados (CEBRIÁn, 1998).

\section{La experiencia del Instituto Nacional de la Seguridad Social}

\section{Misión del INSS y Estrategia de Calidad}

En este apartado se impone la tarea de presentar la estrategia actual de calidad del INSS. Para ello, tendremos en cuenta las precisiones conceptuales realizadas anteriormente y situaremos el análisis en un enfoque más amplio de políticas organizativas públicas.

La primera observación que conviene realizar es que quien escribe estas líneas ocupa actualmente responsabilidades directivas en el INSS y como señaló un autor anónimo: "quien está dentro de una organización, no puede, al mismo tiempo, observarla desde fueran. La posible objeción del lector de cara a la validez y fiabilidad de la valoración que se realiza, se intentará paliar desde la objetividad, de un modo no dogmático, siguiendo las metodologías y los criterios de evaluación utilizados comúnmente para el análisis de las estrategias de calidad de determinados servicios públicos europeos (POLIT y BoucKaERT, 1995) y el estudio de algunos autores del caso concreto del INSS (GonZÁlez-Posada, 1994; PaRRado-Díez y Ruiz López, 1997).

\section{El INSS como organización de servicio}

El Instituto Nacional de Seguridad Social fue creado en la reforma institucional promovida por el Real Decreto-Ley 36/1978, como Entidad Gestora del Sistema de Seguridad Social con personalidad jurídica propia. Adscrita al Ministerio de Trabajo y Asuntos Sociales, tiene encomendada la gestión y administración de las prestaciones económicas del Sistema de Seguridad Social. En la actualidad administra más de siete millones de peńsiones, gestiona y reconoce cada año más de un millón de nuevas prestaciones, dispone de más de trece mil empleados públicos y un presupuesto superior a los siete billones de pesetas. Su gestión se realiza en el ámbito nacional a través de la Dirección General y en la esfera provincial a través de cincuenta y dos Direcciones Provinciales y más de cuatrocientos Centros de Atención e Información de la Seguridad Social (CAISS), en los que se atienden más de veinte millones de consultas anuales.

Las iniciativas de calidad emprendidas por el INSS no disfrutan dentro de la organización del privilegio de ser el centro exclusivo de interés y esfuerzo. Se integran en un planteamiento estratégico global cuyos objetivos inmediatos se hallan enmar- 
cados en los planes de acción del Ministerio de Trabajo y Asuntos Sociales. Como todo organismo público está sujeto a los principios básicos que deben presidir la actividad de la Administración estatal que, fundamentalmente, vienen recogicios en el artículo 103 de la Constitución, así como en el Ley 6/1997, de Organización y Funcionamiento de la Administración General del Estado (LOFAGE). De entre ellos, el servicio a los ciudadanos es el principio básico que justifica su existencia y que preside su actividad.

Este servicio a los ciudadanos y al interés público se caracteriza por la objetividad, es decir, por la transparencia en la actividad administrativa, que constituye no sólo una garantía para los ciudadanos, sino un criterio de actuación general. Junto al principio de legalidad de la actividad administrativa, también el funcionamiento de la Entidad se adecua a la gestión por objetivos y a la calidad como forma ordinaria de prestación de los servicios públicos, dando así cumplimiento al principio de eficacia en la gestión.

Por otro lado, sin dejar de atender los objetivos sociales, propios de un sistema de protección social pública, se concede la debida importancia a los resultados económicos. La Administración de la Seguridad Social no puede ser ajena a la eficiencia y singularmente en el caso del INSS, donde juega el sostenimiento económico social, es preciso mantener y mejorar la excelencia gestora. Todo esto sin olvidar la necesaria convergencia con los parámetros macroeconómicos de los restantes países de la Unión Europea, que se traduce en un escenario de rigor presupuestario.

\section{Conceptualización de los modelos de calidad}

Las investigaciones actuales sobre la aplicación de modelos de calidad a organizaciones públicas complejas, como es el INSS, sugieren que no hay un modelo que sea el mejor para todas las circunstancias. Los métodos que estudian segmentos completos de usuarios pueden ser muy útiles a la hora de proporcionar una primera identificación amplia de las dimensiones relevantes, pero requieren un trabajo detallado si se desea identificar las relaciones entre las diferentes dimensiones de calidad. Por su parte, los modelos destinados a averiguar las preferencias concretas del público objetivo suelen ser enfoques amenos malos" para establecer esas relaciones, pero incluso éstos tienen sus limitaciones (BRUNNEL UNIVERSITY, 1993).

Además, los modelos a elegir en el Instituto para reforzar la calidad de sus servicios debían ser fruto de una amplia investigación empírica, ser susceptibles de implantación en organizaciones públicas y una larga tradición en nuestro entorno cultural; todo ello para asegurar que adoptábamos una estrategia de calidad consistente, asentada en un sistema de valores y un método robusto y comúnmente aceptado.
Dos son los modelos que cumplen estas condiciones, el Modelo aservice Quality Gapso (SERVQUAL) y el Modelo Europeo de Excelencia (Fundación Europea de la Calidad -EFQM-). El primero, desarroliado por PARASURAMAN, ZEITHAML Y BERRY (1993), incide en tres ideas fundamentales:

- la calidad a controlar (diferencia positiva o negativa, entre las expectativas - servicio esperado- y la realidad del servicio que se presta - servicio recibido-);

- el modelo conceptual de calidad de servicio (que vincula las deficiencias que los clientes perciben en la calidad de los servicios con las deficiencias internas que existen en las organizaciones y las causas que las provocan);

- los factores determinantes de la calidad del servicio (dimensiones) - ver figura 17-.

Este modelo se complementa con el de la EFQM para el análisis de las expectativas y percepciones del cliente interno como el externo identificados en el modelo europeo como satisfacción del personal y satisfacción del cliente.

Por su parte, el Modelo Europeo de Excelencia constituye una herramienta de autodiagnóstico de las organizaciones que les permite medir la madurez de su sistema de gestión de Calidad y establece pautas para la mejora continua (ver figura 18). Por ser suficiente conocido el modelo vigente, hemos preferido adelantar las formulaciones que se contemplan en el primer borrador del Nuevo Modelo de la EFQM, al que hemos tenido acceso (Price Waterhouse, 1998). Éste contiene las siguientes definiciones:

- Resultados. Evalúa el nivel de excelencia de la organización en proporcionar valor a los grupos interesados. Informa sobre la efectividad y eficiencia de la organización. Los logros alcanzados están comparados con la percepción de los grupos interesados, objetivos propios y comparaciones con organizaciones externas.

- Enfoque. Encamina la fase estratégica y de pensamiento en la organización. La etapa en que se definen el propósito, el rumbo general, los planes y objetivos para cada elemento clave de la organización junto con el diseño y desarrollo de la manera más eficaz de alcanzarlos (procesos).

- Despliegue. Representa la traducción en hechos de lo que está definido en el enfoque. Comunicación, aceptación y ejecución dan forma a la estrategia de la organización en la gestión sistemática, diaria, de los procesos en todos los niveles de la organización.

- Evaluación y Revisión. Se refiere a los mecanismos en uso que garantizan el control y medida sistemática de todas las actividades clave. El objeto es adquirir aprendizaje e identificar oportunidades de mejora. 


\section{Fitgersen 17}

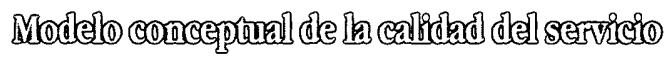

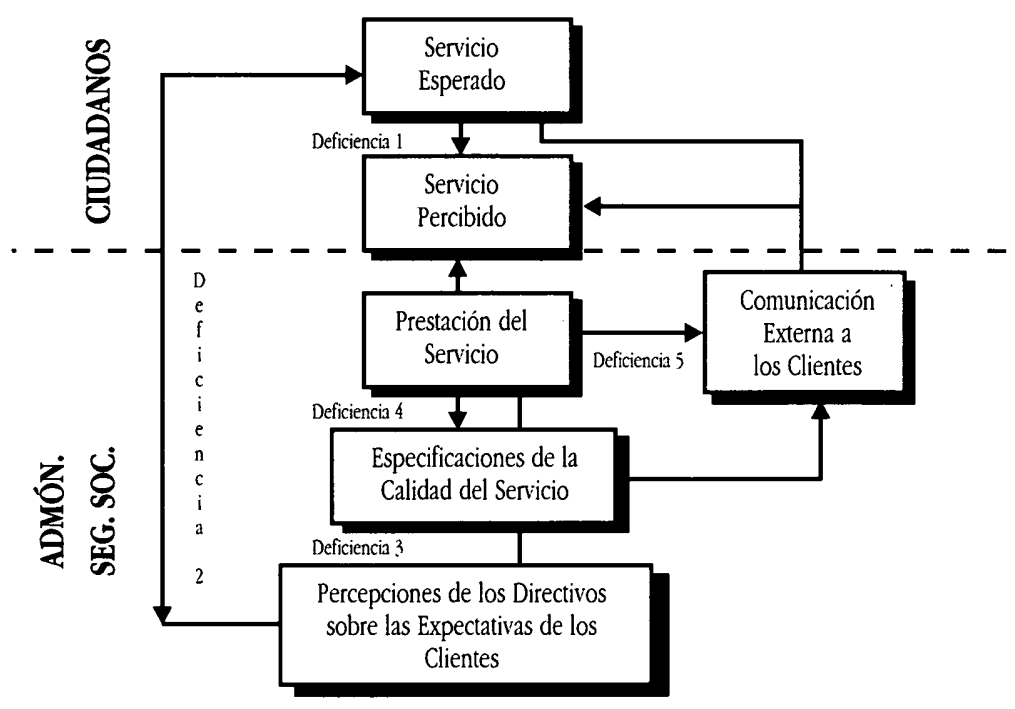

Fuente: Elaboración propia y PARASUMARan, ZeITHAML y BerRY (1993).

\section{Irisarem 138}

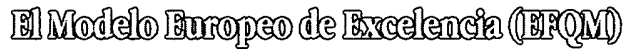

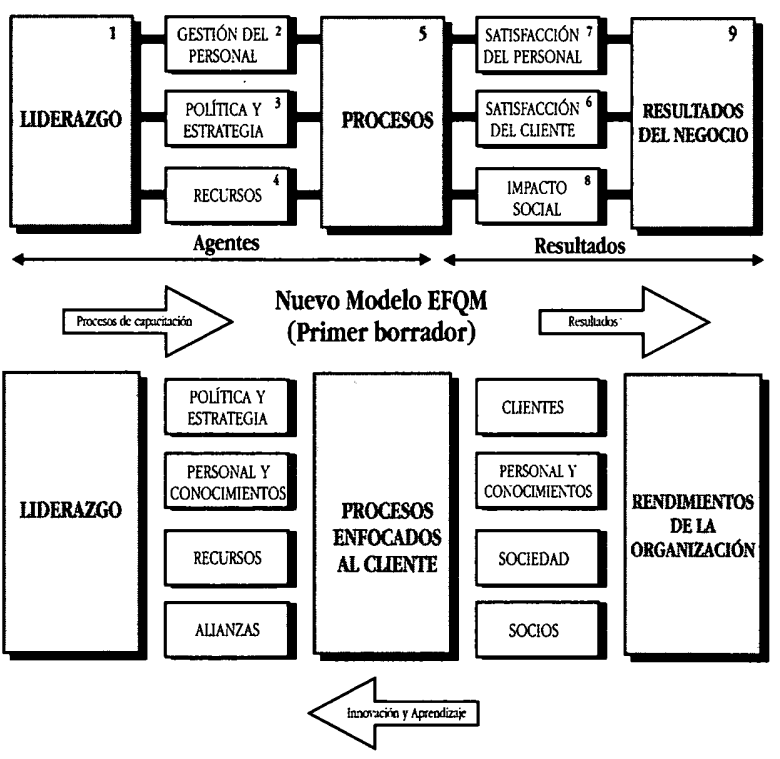

El Instituto Nacional de la Seguridad Social se ha decantado por adoptar ambos modelos para avanzar en su estrategia de calidad, sin descartar la aportación de otros, para reforzar los aspectos relacionados con el diseño de la producción de los servicios, de acuerdo con los requisitos y necesidades de los clientes y los objetivos del Instituto.

\section{Aplicación del Modelo SERVQUAL (1996-1998) ${ }^{1}$}

\section{Marketing de "primera generación"}

El examen del marketing de primera generación (HeRmel y ROMAGNI, 1990), al que hemos hecho referencia anteriormente 
desde la perspectiva de una Administración amable. o de amejora del punto de encuentro con los ciudadanos, constituye una oportunidad de mejora notable para la gestión con calidad. Los instrumentos del marketing nos pueden permitir dár rèspuesta a preguntas como: quiénes son los usuarios del servicio o los potenciales; qué relación existe entre servicio y demanda; qué desean los usuarios de un servicio; qué es lo que de hecho reciben; qué desean los usuarios potenciales; con qué dificultades se encuentran las personas que utilizan el servicio; cuáles son las causas de dichas dificultades.

El modelo del profesor Parasuraman (Universidad de Miami, EE.UU., 1993) constituye una referencia muy extendida para la medición de la calidad en organizaciones de servicio y la herramienta a utilizar se denomina SERVQUAL (Service Quality). El desarrollo de este enfoque, innovador y rico en implicaciones para la gestión, permite identificar las causas de la no calidad (CrosBY, 1987) y ofrece líneas de actuación para solucionar los problemas y deficiencias en la relación de intercambio con los clientes (OLIETE CAB̈ESTKÉ, 1998).

A la hora de implementar la gestión de la calidad total, en el Instituto Nacional de la Seguridad Social, hemos tenido en cuenta que, cualquiera que sea el modelo elegido, ha de respetar las cuatro características que se desprenden de los enfoques surgidos de la OCDE y de la Unión Europea: receptividad hacia el consumidor de servicios públicos; evaluación y seguimiento de los procesos y servicios; la calidad como proceso de mejora continua; y la participación del personal. Además, el modelo SERVQUAL cumple con las cuatro características a las que se debe plegar para la implementación de la gestión de calidad areformada» en la Administración Pública (ver figura 19).

\section{Fingersent 19}

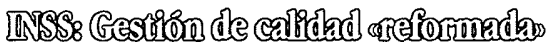

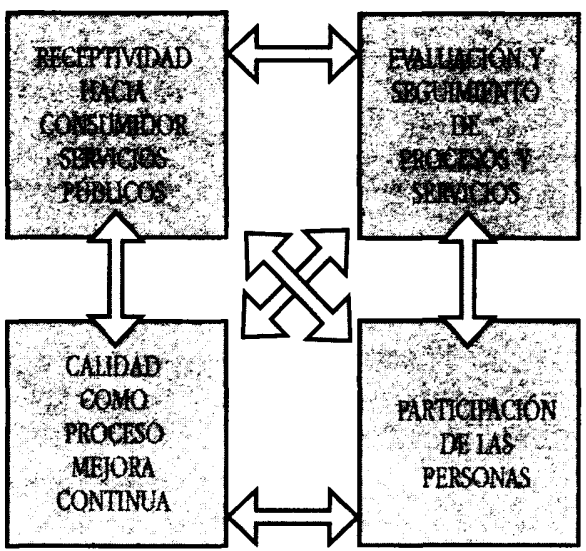

La primera de ellas, la receptividad hacia el consumidor de servicios públicos, es consustancial al modelo SERVQUAL, puesto que define la calidad a controlar como la diferencia, positiva o negativa, entre las expectativas - servicio esperado- y la realidad del servicio que se presta - servicio recibido- Este juego de expectativas y percepción entronca este modelo con los estudios generales de marketing de los servicios y por tanto podemos hacer uso de uno de los axiomas de esta ciencia: cada servicio tiene un público objetivo y cada público objetivo requiere un servicio especializado para ellos.

La segunda característica que debe cumplir el modelo SERVQUAL, la evaluación y seguimiento de los procesos y servicios, es uno de los puntos fuertes de este modelo puesto que vincula las deficiencias que los clientes perciben en la calidad de los servicios con las deficiencias internas que existen en las organi- zaciones, identifica las causas que las provocan y proporciona un sistema de evaluación de las mismas.

La tercera característica, la calidad es un proceso de mejora continua, está implícita en el modelo del profesor PaRASURAMAN, ya que las expectativas de los usuarios son cambiantes en el tiempo y exige de la organización un proceso de readaptación constante, para tratar de estrechar la brecha existente entre expectativas y percepciones o mantener los niveles de excelencia, si es el caso.

Por último, la cuarta característica, la participación del personal, tiene su reflejo en el modelo SERVQUAL en la determinación de deficiencias concretas que afectan tanto al personal directivo, que puede tener una percepción errónea de las expectativas de los usuarios, como al de primera línea, que puede no estar capacitado o motivado para realizar un servicio con el nivel de calidad requerido. 
Elaboración de objetivos e indicadores sobre la calidad de los servicios

Obviamente, la forma concreta en que se lleve a cabo la conceptualización de la noción de calidad determinará qué tipos de datos es preciso recabar. Una regla podría ser que cuanto mayor sea el papel asignado a los usuarios en la definición de la calidad, más complejos y variados han de ser los modos de aplicación operativa y la obtención e interpretación de los datos (Polut, 1995). Así, el papel preeminente asignado a los clientes del INSS ha supuesto la necesidad de establecer normas internas y realizar encuestas periódicas para averiguar el nivel de satisfacción de los usuarios de los servicios.

Por otra parte, todo proceso de evaluación requiere la definición con claridad de los criterios de valoración. Para que esta valoración resulte estimable para una gestión positiva, la actividad desarrollada ha de ser correcta y fiable, operativa y justificada. La valoración es algo más que desarrollar medidas de brillante solución técnica, recopilar datos, procesarlos y distribuir información. Es preciso satisfacer tres tipos de requisitos (BOUCKAERT, 1995):

- Validez y fiabilidad: calidad de la valoración. Un sistema útil para evaluar la calidad ha de ser lógico, razonable, convincente y expresar lo que pretende demostrar. Una evaluación fiable debe guardar un equilibrio en cuanto al lugar y el tiempo. En consecuencia, las valoraciones fiables se deben poder repetir en cuanto al lugar y tiempo, han de ser claras, precisas y exhaustivas. La posibilidad de repetición es fundamental para efectuar comparacionies en el tiempo, entre lugares distintos y con estándares y normas.

- Funcionalidad frente a disfuncionalidad. No resulta suficiente que las medidas sean correctas desde el punto de vista técnico. La evaluación debe apoyar el propósito de la organización. Las medidas disfuncionales pueden ser válidas y fiables, pero ponen en peligro o inhiben la consecución de los objetivos de la organización. En el ámbito de los servicios sociales, la valoración del resultado, entendido como el número de casos tramitados, puede dar lugar a que se concluyan casos sin analizar por completo si tal solución era correcta. A pesar de que el número de casos cerrados constituya una medida válida y fiable, puede tener consecuencias disfuncionales. Considerar el número de casos concluidos correctamente, daría también como resultado una medición válida y fiable.

- Legitimación y titularidad. Es posible que el sistema de valoración, que consta de las propias mediciones, los procedimientos para recopilar datos, procesarlos y distribuir esta información, no funcione como debiera. Esto podría ocurrir hasta el punto de que quienes deban usar el sistema lo consideren poco fiable o lo rechacen. La titularidad y la legitimidad deberán estar definidas en un sentido amplio. Los ciudadanos y los usuarios, asi como el personal que proporciona los servicios, pueden ser demandados acerca de cuáles son las medidas que se deben adoptar para evaluar la calidad. Involucrar conjuntamente a los ciudadanos, profesionales y funcionarios para desarrollar un sistema de valoración aumenta las posibilidades de que la evaluación de la calidad sea abordada con seriedad y resulte efectiva.

En la adaptación del modelo SERVQUAL a la realidad social y cultural del INSS podemos distinguir varias fases:

- Primera Fase: Determinación del "público objetivo" del INSS

Atendiendo a la naturaleza de los servicios que se prestan en el INSS, se han diferenciado tres grandes colectivos de clientes:

- Los solicitantes de información general. Este segmento lo conforman todas aquellas personas que se dirigen a nuestros centros solicitando información sobre los requisitos para causar derecho a las prestaciones gestionadas por el INSS.

- Los nuevos perceptores de prestaciones. Es el colectivo de personas a las que se les reconoce cualquiera de las prestaciones económicas gestionadas por el INSS.

- Los pensionistas. Es el colectivo de personas que tienen una pensión reconocida y mantienen una relación de intercambio permanente con el Instituto.

\section{- Segunda Fase: Determinación de las expectativas de los clientes}

Como paso previo a la implantación del sistema de medición de la calidad SERVQUAL y una vez segmentada la totalidad de los clientes usuarios del INSS, que permitiera la adopción de decisiones correctas encaminadas a mejorar la percepción del cliente sobre el servicio recibido, se diseñaron tres encuestas diferenciadas, dirigidas a cada uno de los segmentos de clientes, cuyo objetivo fue conocer las expectativas o deseos de dichos colectivos, es decir, su modelo ideal de prestación de servicio.

El trabajo de campo del estudio de expectativas se desarrolló en veinte Direcciones Provinciales, seleccionadas de forma que fuesen representativas de acuerdo con criterios de volúmenes de gestión, distribución por Comunidades Autónomas y dispersión/concentración 
de la población, con una muestra de más de 400 unidades para cada segmento. En total, se llevaron a cabo 1.229 entrevistas, aplicándose un cuestionario específico para cada segmento. En cada uno de los centros donde se realizaron las entrevistas se tomaron medidas para que la selección de las personas fuera aleatoria, variando las bandas horarias y entrevistando a todos los clientes posibles sin descartar a ninguno por sus características visibles. Tratándose de un estudio sobre expectativas de calidad, las entrevistas fueron realizadas antes de que el entrevistado realizara la gestión que motivaba su asistencia al centro. De esta manera se buscó evitar la contaminación de las expectativas por las percepciones del servicio realmente recibido.

En el modelo SERVQUAL se entiende la calidad del servicio como la percepción u opinión que tienen los usuarios respecto del servicio que han recibido. Esta percepción del servicio está constituida. por dos elementos, lo que espera recibir el usuario y lo que cree que ha recibido.

Según este modelo existen cinco dimensiones generales o características genéricas que subyacen en la prestación de cualquier servicio y que sirven para englobar todas las características específicas o componentes del servicio que se consideran fundamentales para el cliente:

- Capacidad de respuesta. Es la disposición o voluntad para ayudar a los usuarios y proporcionar un servicio rápido. Desde este punto de vista, las organizaciones cuyos clientes no pueden comunicarse con ellas por estar saturadas las líneas telefónicas o que tienen largas colas en sus locäles, presentan baja capacidad de respuesta.

- Atención individualizada (empatía). Significa ponerse en el lugar del ciudadano, comprender sus necesidades particulares y encontrar la respuesta más adecuada.

- Fiabilidad. Es la habilidad para realizar el servicio prometido de forma fiable y cuidadosa. Se trata de evitar los errores del servicio, que no sólo son caros de corregir en sentido estricto, sino también indirectamente, porque tienen un efecto negativo sobre la confianza del cliente en toda la institución.

- Seguridad. Conocimientos y habilidades de los empleados para demostrar credibilidad y confianza. Significa la competencia profesional y la cortesía del personal que presta el servicio.
- Elementos materiales (elementos tangibles). Apariencia de las instalaciones físicas, equipos, personal de contacto y materiales de comunicación. Los elementôs materiales sôn la parte visible de la oferta de servicio. Las cosas tangibles influyen en la percepción de la calidad del servicio que, de una manera simbólica, dan una idea de la naturaleza y calidad del servicio y, de una manera directa, hacen el contacto con la Institución más agradable.

Los resultados de la investigación de la importancia relativa que nuestros clientes otorgan a las cinco dimensiones fundamentales de la calidad del servicio (ver figura 20), ofrece resultados muy similares en los tres segmentos estudiados:

- Fiabilidad: varía entre un 30\% y un $29 \%$.

- Seguridad: varía entre un $24 \%$ y un $23 \%$.

- Capacidad de respuesta: varía entre un $22 \%$ y un $21 \%$.

- Atención individualizada (empatía): varía entre un $20 \%$ y un $19 \%$.

- Elementos materiales (tangibles): es constante e igual a un $6 \%$.

El resultado del estudio del peso relativo de los diferentes componentes de cada dimensión, también refleja resultados muy semejantes en los tres segmentos, y permitió cuantificar, en una escala de cero a diez, las expectativas del servicio (ver figura 21).

- Tercera Fase: Diseño de cuestionarios de evaluación del servicio recibido

Conocidas las expectativas de los clientes, el siguiente paso fue el diseño de tres cuestionarios, diferenciados para cada uno de los segmentos de nuestros clientes, que son el instrumento de medición para valorar, ya no expectativas, sino la percepción del servicio recibido.

En la actualidad, el cuestionario de evaluación se aplica, de manera permanente, al segmento de nuevos perceptores de prestaciones (pensiones y subsidios), a quienes se remite junto con la resolución aprobatoria de la prestación. La valoración del servicio que este colectivo expresa a través del cuestionario, integrado por quince preguntas o componentes, constituye la base para la medición de la calidad de los servicios en el INSS (ver figura 22). Las encuestas a los solicitantes de información general y a los pensionistas tienen carácter anual y se realizan en el primer y segundo semestre, respectivamente, mediante la entrega directa del cuestionario por 
Fingeract 20

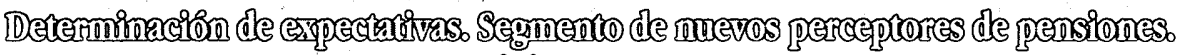

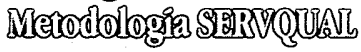

IMPORTANCIA RELATIVA

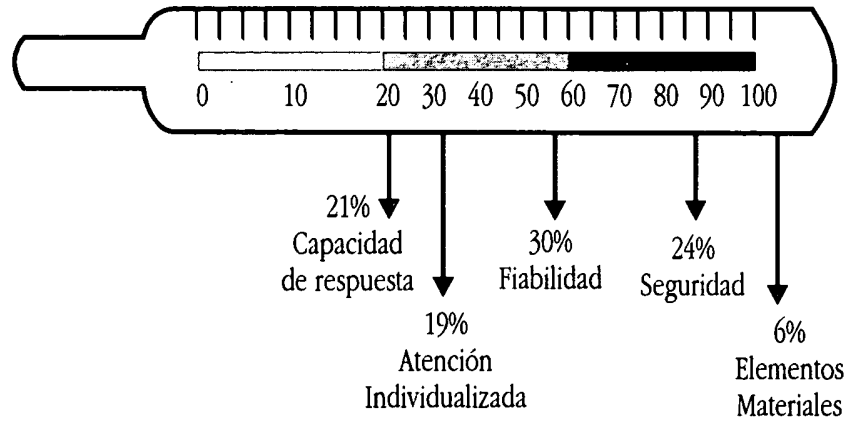

Fenger 21

Resultertos - Neivel de callitad global 1928

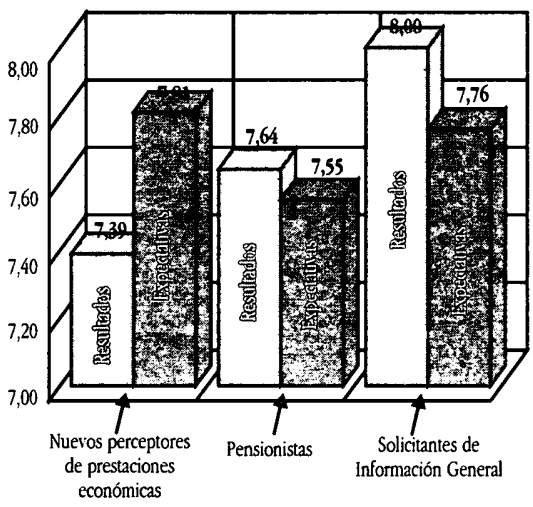

los funcionarios de los Centros de Atención e Información del INSS.

- Cuarta Fase: Fijación de objetivos de calidad de los servicios

A partir del segundo semestre de 1996, se fijaron nuevos objetivos de calidad de los servicios, basados en el sistema de medición SERVQUAL. El objetivo a medio plazo debía superar o al menos igualar las expectativas de los clientes del Instituto. Cabe diferenciar los objetivos de calidad de los servicios de los objetivos de gestión de la información. Ambos se fijan anualmente para su cumplimiento a las Direcciones Provinciales del Instituto y configuran uno de los componentes de la productividad vinculada a los rendimientos y a la Gestión por Objetivos globales de la Entidad.
Objetivos de calidad de los servicios

Partiendo de estas formulaciones, los objetivos de calidad de los servicios se formulan en el INSS sobre las dimensiones de calidad, ya que se considera que un buen sistema de objetivos e indicadores debe ser reducido en su número y claro en su formulación. Para ello, en las encuestas de expectativas, a las que se ha hecho referencia anteriormente, además de la opinión sobre el servicio esperado a nivel de componente, se solicitó la opinión sobre la importancia que para nuestros clientes tenía cada uno de ellos dentro de cada dimensión (acoeficiente" que mide el peso relativo de cada componente dentro de su dimensión). La aplicación de estos coeficientes a las valoraciones de los componentes obtenidas en la encuesta, determina el nivel de exigencia institucional a nivel de dimensión, que constituye el nivel máximo de expectativas de nuestros clientes. 
Irigerara 222

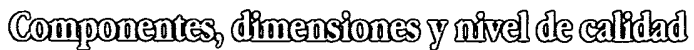

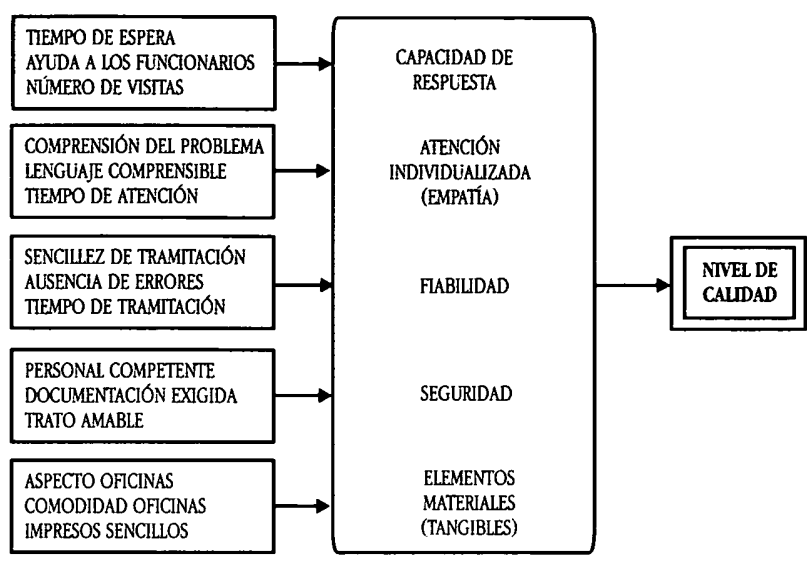

De acuerdo con todo lo expuesto, se fijan objetivos de calidad del servicio a dos niveles, institucional y provincial. A medio plazo, los objetivos del Instituto deben igualar o superar los niveles de exigencia institucional y provincial. Sin embargo, se considera que la consecución de estos resultados debe hacerse de forma gradual, por lo que durante el primer año de vigencia de este nuevo sistema (1996), se fijaron unos objetivos que pretendían alcanzar un $85 \%$ de los niveles de exigencia en la prestación del servicio de pensiones y del 75\% en el de subsidios, mientras que en 1997 se incrementaron hasta exigir el 95\% y el $85 \%$ respectivamente; para 1998 se han elevado al 100 por 100 (pensiones) y 90 por 100 (subsidios).

Los objetivos de calidad de los servicios se fijan por igual para todas las Direcciones Provinciales por las siguientes razones:

- La valoración de las expectativas sobre la calidad del servicio obtenidas en las encuestas realizadas en veinte Direcciones Provinciales, que, como ya se ha señalado más arriba, fueron seleccionadas para garantizar la validez de las muestras, arrojaron resultados prácticamente idénticos en cada una de ellas.

- La normalización de los procedimientos de gestión, el grado de informatización y el nivel de formación de los funcionarios, en el conjunto de las Direcciones Provinciales del Instituto son muy similares, por lo que en principio no existen factores fundamentales que justifiquen una diferencia en los niveles de calidad en la prestación de los servicios.

(Los indicadores de la calidad de los servicios para cada segmento de usuarios se reflejan en las figuras 23,24 y 25).
Objetivos de gestión de la información

Se formulan en este apartado una serie de objetivos e indicadores que miden la calidad de los servicios desde la perspectiva de los procesos internos de gestión en las áreas de atención e información, y que recogen determinados aspectos que no pueden ser evaluados desde el punto de vista de la opinión de los clientes, por poner en relación la actividad informativa con otros parámetros internos de gestión (expedientes iniciados y en trámite y plantilla de informadores) - ver figura 26-

Los objetivos de gestión de la información que se formulan son los referidos a Presentación de Documentación, Trámite de Prestaciones y Rendimientos de la Actividad Informativa.

\section{PRESENTACIÓN DE DOCUMENTACIÓN}

Mide la relación entre el número de consultas de presentación de documentación de cada una de las prestaciones, y el número de expedientes iniciados de las mismas, en un determinado período. Dicha relación debe arrojar un índice no inferior a la unidad ya que, en circunstancias normales, debe existir al menos una consulta por cada expediente iniciado (ver figura 27).

\section{TRÁmite DE PRESTACIONES}

Mide la relación entre el número de consultas sobre el trámite de una determinada prestación, y el número de expedientes en trámite de la misma, en un determinado período. Dicha relación debe arrojar un índice ideal de cero ya que una vez iniciado cualquier expediente el interesado no debe volver a las 

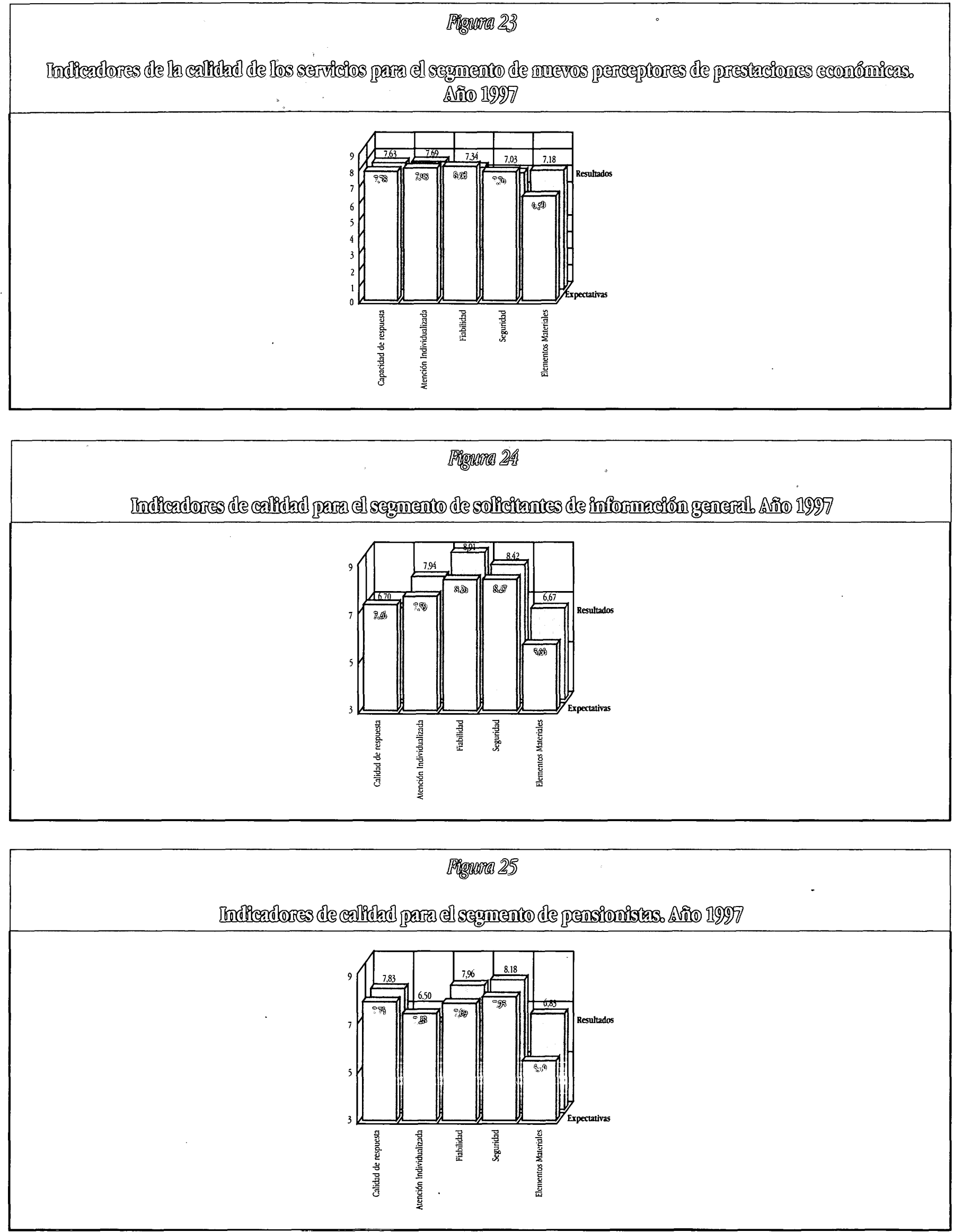

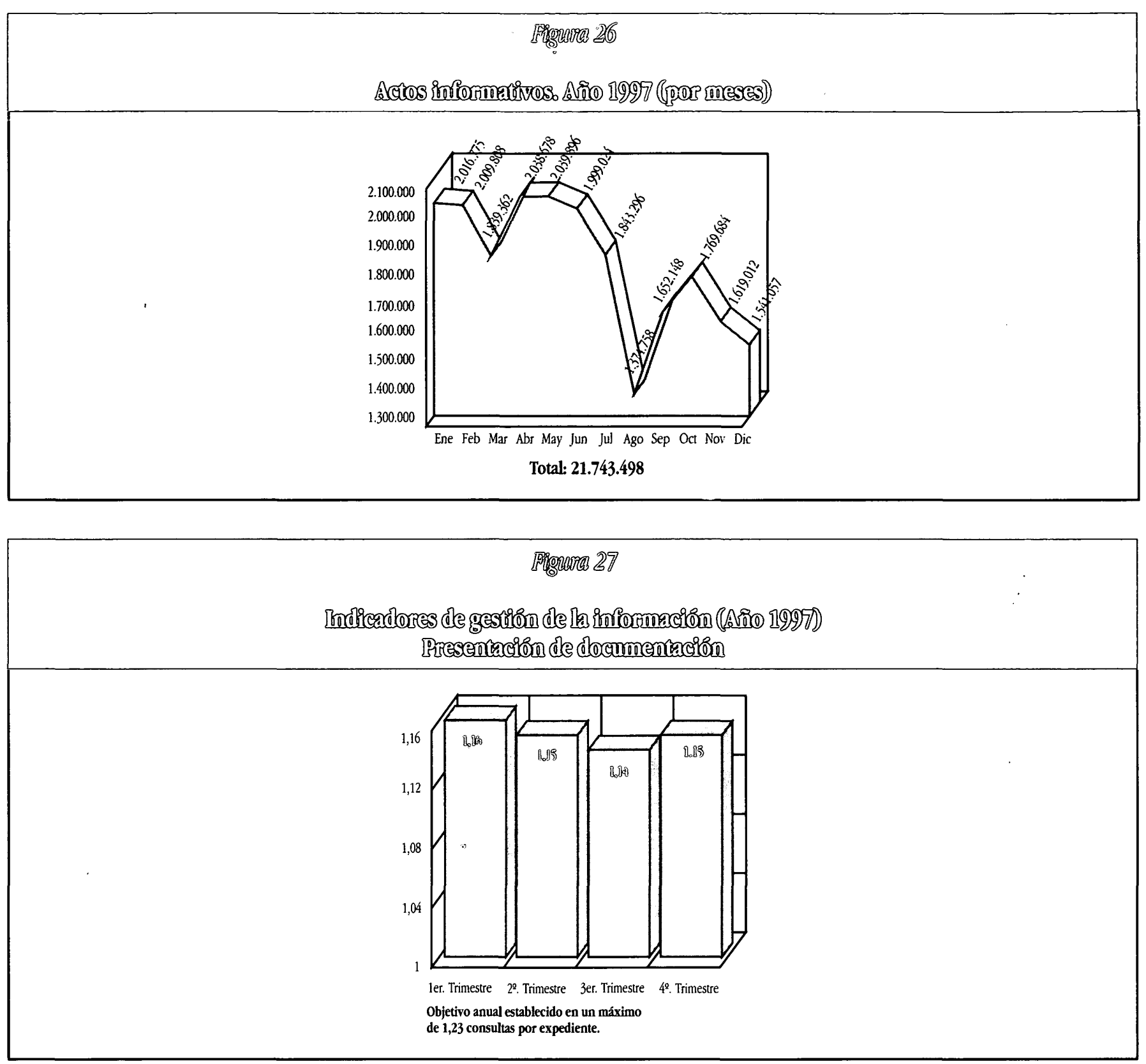

oficinas del Instituto para interesarse por el estado de su expediente (en términos coloquiales se trata de romper el viejo tópico de "vuelva usted mañana") - ver figura 28-.

\section{RENDIMIENTOS DE LA ACTIVIDAD INFORMATIVA (CONSULTAS} FUNCIONARIO/DÍA)

Mide la relación entre el número de consultas atendidas y el potencial útil de trabajo en un determinado período, para obtener el número de consultas atendidas por funcionario y día. Este objetivo se formula como un intervalo de valores y la razón fundamental estriba en tomar en consideración las circuns- tancias que a lo largo de un año pueden afectar a la plantilla de las Direcciones Provinciales y a su red de Centros de Atención e Información de la Seguridad Social (CAISS) que inciden directamente en el cálculo del indicador (ver figura 29).

LÍNEA 900

El INSS dispone, además, de nueve plataformas de atención e información telefónica gratuita, actualmente sujeta a revisión y adecuación a las necesidades de los clientes del Instituto (ver figura 30). 


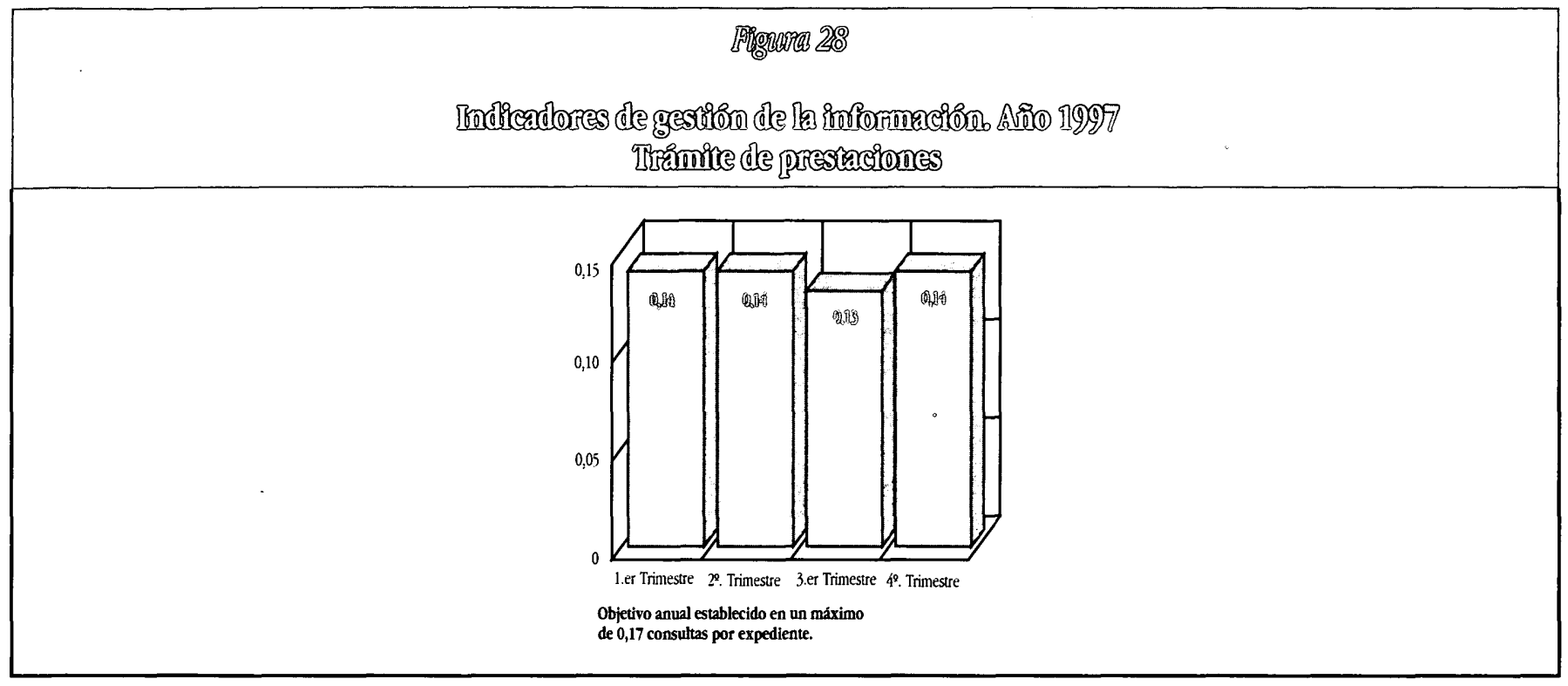

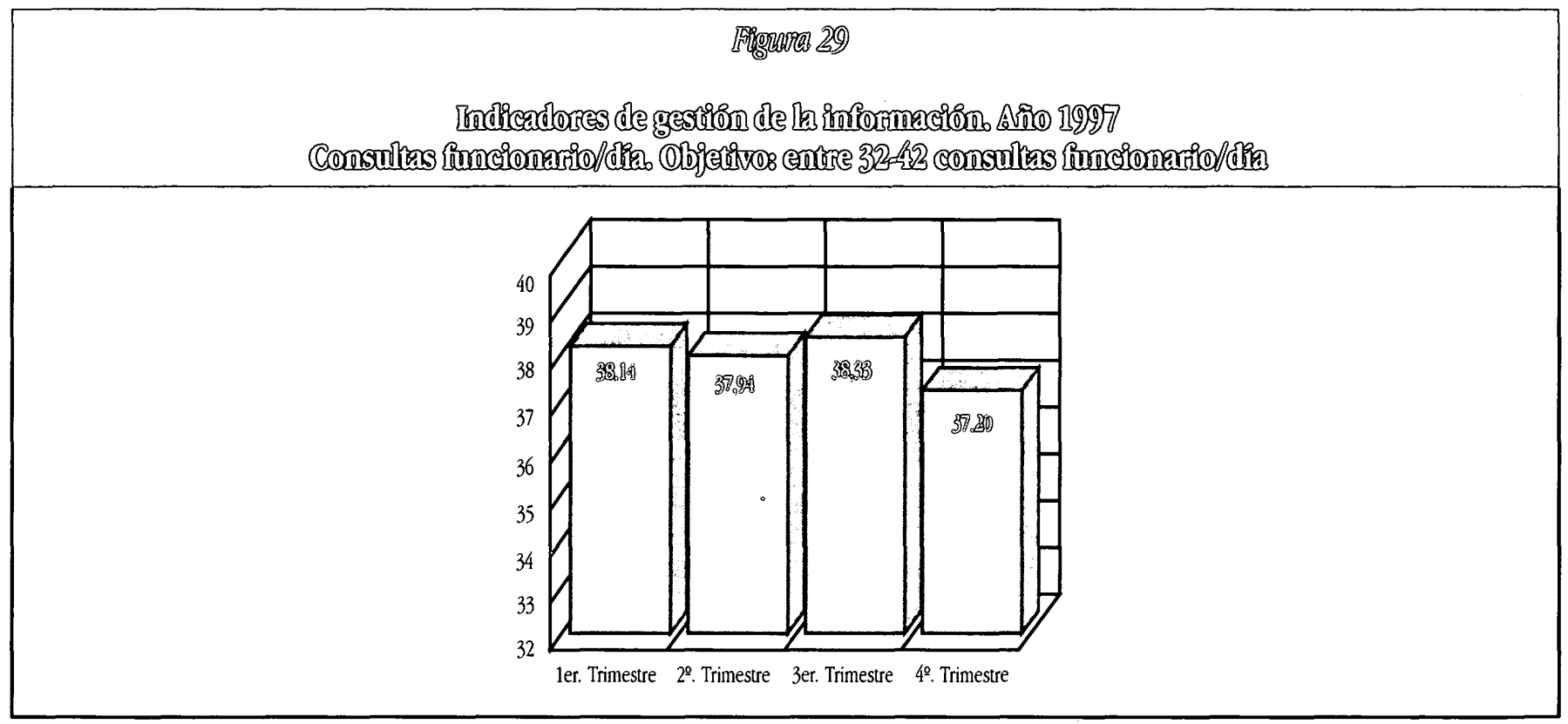

Reconocimiento y validación pública de los resultados de calidad

La evolución de las actividades y de los modelos mentales del público, la creación de asociaciones de consumidores y de defensa de sus intereses, son el origen de una toma en consideración más importante de las necesidades de los ciudadanosclientes en la elaboración de los proyectos públicos. En opinión de Crozier (1995), el Estado nacional ya no tiene frente a sí los mismos actores dispersos, relativamente previsibles que podía dominar fácilmente. El Estado tiene frente a sí a actores más numerosos, más heterogéneos, más independientes, que son capaces de aliarse entre ellos y de funcionar sin respetar fronteras. Estos actores disponen de un gran poder de negociación. Lo- gran penetrar en el Estado e influenciarlo más de lo que ellos mismos son influenciados. LOUPPE y MENGUY (1978) han definido nuevos colectivos que buscan un estatuto de partenaires con las organizaciones públicas: se trata de personas a las que se consulta desde el ámbito público; personas a las que se solicita su concurso para la elaboración de proyectos; personas con las que se negocia, sobre todo para elecciones o proyectos importantes; y personas a las que se solicita su colaboración para el cumplimiento de ciertas misiones.

El INSS no ha sido ajeno a esta tendencia cooperativa y solicitó el concurso de las organizaciones que vertebran a sus clientes. Procedía en este proceso de mejora continua del Instituto, abordar la conversión de la descripción del servicio en características tanto para el servicio como para su prestación y 


\section{Fingerse 30}

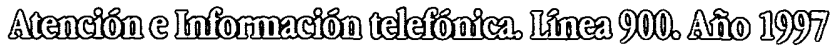

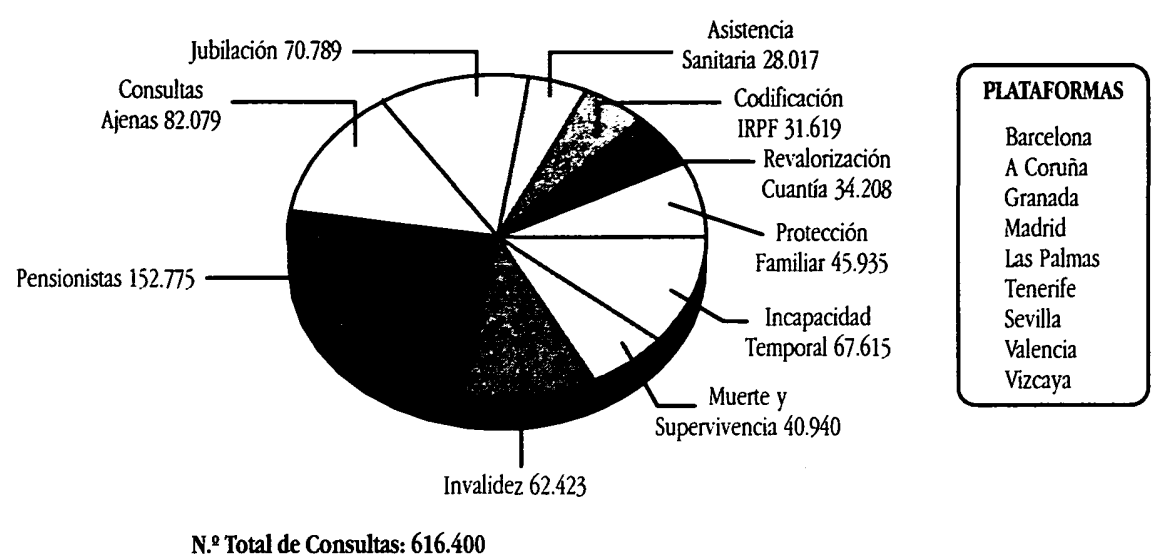

control. Los cuestionarios que se utilizan para pulsar la percepción de los clientes sobre el servicio recibido tienen las lógicas limitaciones de un instrumento de estas características en cuanto al número de los componentes que pueden ser objeto de consulta, así como a la generalidad de su expresión. Esta razón determinó la necesidad de profundizar en la investigación de las características del servicio que demandan nuestros clientes.

La técnica utilizada para investigar las características de la prestación del servicio es la de sesiones de trabajo con colectivos cualificados y líderes de opinión de nuestro sector, en las que se formularían preguntas abiertas, y se recogerían las sugerencias y observaciones de los diferentes grupos de participación. El Instiuto considera como tales a:

- las asociaciones de consumidores de ámbito nacional y de reconocida influencia;

- las asociaciones de pensionistas que tienen como objeto la defensa de los intereses de este colectivo y no las de mera promoción de actividades, ya sean culturales o recreativas de las personas mayores;

- los sindicatos y organizaciones patronales más representativas, como agentes sociales que son, interesados por definición en el funcionamiento de los servicios públi$\cos$ y con el añadido de que, en nuestro caso, forman parte por imperativo legal de los Órganos de Vigilancia y Participación del Instituto y a quienes se les rinde cuenta de la gestión de calidad en el Consejo General del INSS, periódicamente.

En la Semana Europea de la Calidad (noviembre de 1997), se desarrolló una reunión de trabajo en la que se expuso a los representantes de las organizaciones convocadas el modelo de calidad adoptado, los resultados alcanzados, consiguiendo la validación de la calidad del servicio ofrecido por el INSS, por parte de las organizaciones presentes ${ }^{2}$.

\section{El Modelo Europeo de Excelencia (EFQM) y el INSS ${ }^{3}$}

\section{La autoevaluación como requisito previo}

Como señala la Fundación Europea para la Gestión de Calidad (EFQM, 1996), durante muchos años, las organizaciones comerciales han evaluado el progreso alcanzado comparándolo con distintos modelos de excelencia. El primero de estos modelos fue el Premio Deming de Japón, al que siguió en EE.UU el Premio Baldrige y, recientemente, el Premio Europeo a la Calidad. Algunas organizaciones evalúan su progreso solicitando uno de estos premios, si bien la mayoría logran su objetivo aplicando uno de los métodos de autoevaluación. Cada organización es única en cuanto a la naturaleza de su negocio y el énfasis que pone en cada uno de los distintos grupos que tienen algún interés en ella (clientes, empleados, proveedores, sociedad, ...), por lo que debe interpretar el Modelo de acuerdo con su situación particular.

En los últimos años se ha hecho patente que los modelos de calidad que se aplican a las empresas pueden aplicarse de igual manera a las organizaciones del Sector Público (aunque con las adaptaciones oportunas como se ha señalado anteriormente). En consecuencia, este Sector puede también beneficiarse de la autoevaluación a la hora de definir sus puntos fuertes y áreas de progreso con el fin de incluirlos en sus planes y garantizar así la mejora continua, esencial en toda organización actual. Se considera importante utilizar un modelo de uso generalizado, ya que esto facilitará la comparación no sólo entre organizacio- 
nes pertenecientes a distintas áreas del Sector Público sino, también, entre el Sector Público y las empresas. Por otra parte, la EFQM utiliza el mismo modelo como base del Premio Europeo a la Calidad para organizaciones del Sector Público. Esto proporciona un enfoque consistente de autoevaluación que, finalmente, desembocará en el establecimiento de estándares comunes (EFQM, 1996).

Las organizaciones del Sector Público consideran algunas veces que el Modelo EFQM es relevante con respecto a los cinco Agentes Facilitadores (Liderazgo, Gestión del Personal, Política y Estrategia, Recursos y Procesos), pero más difícil de aplicar en cuanto a Resultados (Satisfacción del Cliente, Impacto en la Sociedad y Resultados Empresariales). Por lo general, para clarificar estos temas, la organización debe:

- situar y definir claramente a todos los grupos con algún interés en ella y, sobre todo, a sus clientes;

- darse cuenta de que aunque muchas organizaciones del Sector Público creen que sólo existen para tener un impacto en la sociedad, los resultados del trabajo habitual de la organización van dirigidos a los clientes antes mencionados. En el criterio Impacto en la Sociedad se contemplan las áreas relevantes que escapan a las actividades habituales de la organización;

- los resultados empresariales, económicos y no financieros, son clave para cualquier organización. En las organizaciones del Sector Público, el logro de los objetivos y las tendencias positivas en materia de gastos, precio por unidad de producción y otros muchos factores económicos, son fundamentales a la hora de alcanzar un éxito sostenido. Por otra parte, existen además numerosos indicadores no financieros para medir el éxito, y que son específicos de cada organización.

Todos estos aspectos refuerzan el hecho de que toda organización es única y debe dedicar tiempo a situarse con relación al Modelo EFQM. Tras esta inversión inicial de tiempo, el Modelo constituye un punto de partida excelente para alcanzar mejoras (EFQM, 1996).

\section{Un enfoque avanzado para la gestión eficiente}

El proceso de mejora continua que el INSS viene desarrollando en los últimos años. está sometido, en la actualidad, a una profunda reorientación que pretende establecer parámetros de referencia básicos que permitan que el servicio público que tiene encomendado se reciba y perciba por sus clientes desde la superación de sus propias expectativas. Esa exigencia requiere, por un lado, un análisis sistémico, valorativo y puntual, de la identidad y requerimientos de sus clientes (ciudadanos, empre- sas y otras organizaciones); por otro, una profunda reordenación de las "formas y sistemas de producción" y los contextos en que se desarrollan.

Desde esa exigencia el INSS, desde 1997, ha asumido metodológicamente los enfoques más avanzados sobre gestión organizativa, impulsando una serie de reflexiones de carácter interno, orientadas al análisis y valoración de los parámetros conceptuales que conforman el Modelo Europeo de Calidad $(E F Q M)^{4}$. La adecuación, coherente y sistemática del Instituto al citado Modelo exige un esfuerzo de reordenación conceptual y adaptación instrumental en orden a plantear e implantar un enfoque avanzado para la gestión eficiente. Desde esa perspectiva, los objetivos finales, y la consiguiente aspiración institucional, se centran en la actualización de un conjunto de singularidades conceptuales que permiten la proyección estratégica de la Institución: dirección por politicas y prioridades, gestión por procesos, mejora continua e iniciativas/sugerencias de los funcionarios (MERLI, 1997).

Todo lo anterior tiene específicos requerimientos a los que el INSS trata de dar adecuada solución institucional a través de la oportuna elaboración metodológica; este esfuerzo se canaliza a través de sesiones formativas, con una extensa participación del personal de la Organización por medio de tres grupos estratégicamente constituidos: un "grupo de compromiso institucional", un "grupo asesor" y un "grupo operativo" que, desde un riguroso trabajo conceptual, pretenden establecer una aproximación metodológica y conceptual al citado Modelo Europeo de Excelencia.

\section{Hacia la gestión por procesos}

El modo de pensar convencional sobre "producción" en la Administración Pública está excesivamente centrado en la realización de tareas, sin conceder tanta atención a la mejora de procesos y la consecución de resultados (BARZELAY, 1994). La traslación del mundo de los negocios de la buisqueda de beneficio a servir los intereses públicos implica que el servicio público es en sí mismo la única recompensa para la Administración. De forma similar la traslación de producción por procedimientos y actividades administrativas expresa que la Administración opera de forma eficiente si divide sus funciones en tareas muy especializadas, asignando esos deberes a funcionarios bien preparados, los cuales deberán responder de su trabajo ante sus superiores. Estas prácticas y principios -continúa BARZELAY - han conducido a las organizaciones públicas (así como las privadas) a unos niveles de rendimiento que permiten mejoras potenciales significativas, a partir de recursos no explotados. Muchos de los atractivos de las ideas presentes en conceptos como calidad total o reinvención del gobierno (OSBORNE y GAE- 
BLER, 1994) deben ser relacionados con las concepciones que sobre estos temas mantienen los gestores públicos. Algunos de los criterios de las prácticas convencionales alegan que los organismos gubemamentales prestan poca atención a los procesos.

Desde el punto de vista de una estrategia organizativa coherente con el modelo de gestión de servicios se trata de transformar la manera de concebir el proceso interno en cada unidad. Mientras en el modelo garantista la clave de todo descansa en el procedimiento administrativo, al menos en la manera en que los funcionarios entienden su trabajo, en el nuevo modelo fundado en la provisión de servicios, parece más razonable hablar de un proceso de producción y de conceptualizar la actividad administrativa como un proceso, un flujo que tiene por último objetivo la creación de servicios y bienes públicos. La reconceptualización de la actividad de la Administración como un proceso de producción se ajusta a un cambio tanto en la naturaleza intrínseca del trabajo que se lleva a cabo en la mayoría de organizaciones que producen servicios, como en la percepción que los empleados tienen de su trabajo (Borx, 1994).

Una vez el trabajo se conceptualiza como proceso, es posible alinear, desarrollar y medir los conceptos clave de resultado, control de calidad y servicio. Las propuestas de Gestión de Calidad Total revelan cómo es posible integrar la idea de producción y proceso en la gestión de la Administración y medir y evaluar la actividad de esta última (Barzelay, 1992). Por su par- te, OSBORNE y GAEBLER (1994) señalan que las organizaciones que utilizan la GCT miden constantemente sus procesos internos de modo que pueden ver dónde están los problemas y corregirlos. Además, los resultados deseados por cualquiuier organización son a veces difíciles de medir, o no se hacen evidentes hasta que pasa un tiempo. En estos casos, las organizaciones a veces eligen mediciones de procesos que parecen ser aproximaciones fiables a los resultados definitivos. Por tanto, una vía de refuerzo a los instrumentos de análisis de políticas públicas puede venir dada por la Gestión de la Calidad Total (GCT).

El INSS, como organización pública, tiene interiorizado que para ser eficaz y eficiente ha de transformar su gestión por funciones en gestión por procesos y que la mejora de los mismos requerirá, en todo caso, una visión compartida de lo que el Instituto pretende ser; para ello, y entre otras prioridades, habrá de dirigir sus potencialidades institucionales a los procesos más críticos en función del impacto que presentan en la consecución de sus objetivos estratégicos (NeGueruela, 1998).

\section{Metodologías de aplicación}

Todo ese propósito transformador, y ya conceptualizado, ha requerido un trabajo metodológico del que a continuación se ofrece una breve sintesis (ver figura 31).

\section{Prengeres 31}

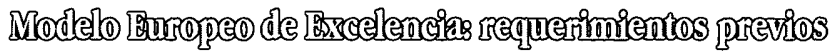

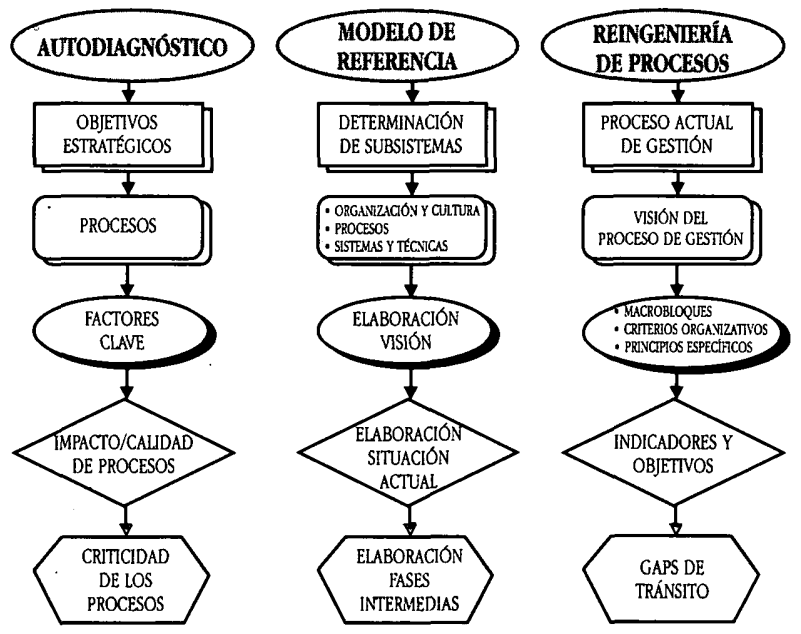

Autodiagnóstico de la Organización

En primer lugar se ha realizado el autodiagnóstico de la Organización en orden a identificar los puntos críticos existentes tanto en el sistema estructural organizativo como en el funcional. Para ello se han establecido, en primer lugar, los objetivos estratégicos del Instituto a través del análisis de sus entornos y de la misión que tiene encomendada; suponen una permanente 
guía de actuación y, como criterios básicos de referencia, una Organización como entidad pública y necesaria para la sociejustificación conceptual y operativa de la propia existencia de la dad (ver figura 32).

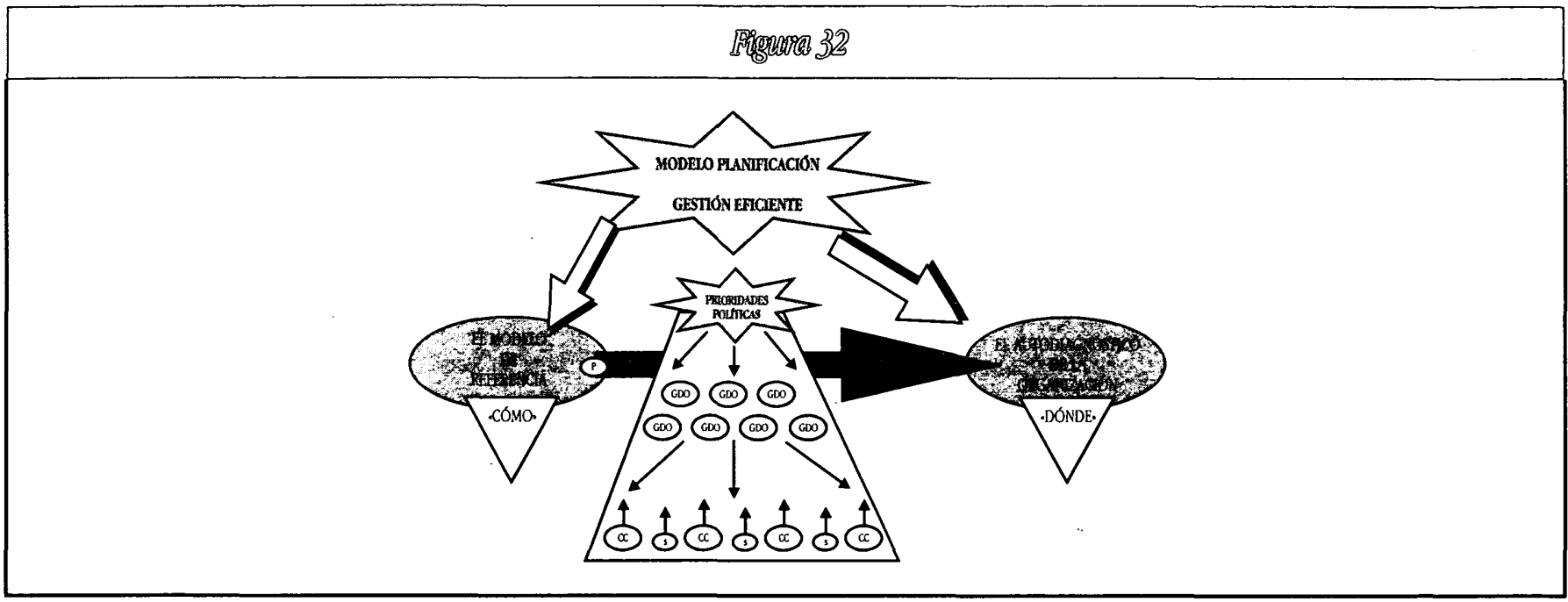

Fuente: NEGUERUELA (1998) y MERL (1997).

Nota: P: Proceso; GDD: Gestión día a dia; CC: Círculo de calidad.

La revisión del entorno funcional de la Institución, desde la referencia de aquellos objetivos, ha permitido establecer la lista de procesos básicos integrados en ese entorno con especificación de los procesos primarios y de los de soporte. Cabe destacar que en el INSS la gestión de prestaciones constituye el único proceso primario que, a su vez, puede presentar específicas singularidades que contrastan con la misión de la Organización. El resto de procesos constituye, en todo caso, soporte para el funcionamiento optimizado del establecido como primario.

En ese discurrir metodológico se hacía necesario, asimismo, determinar la criticidad de los procesos en orden a facilitar a la propia Institución los puntos claves a los que ha de reconducir sus mayores esfuerzos; en la búsqueda de esa criticidad se han determinado los factores clave de la Organización, que constituyen su entramado orgánico y funcional y que permanentemente son afectados por el desarrollo funcional de los procesos.

El cruce de esos factores con la totalidad de los procesos básicos predeterminados se ha realizado desde dos premisas: valoración del impacto de los procesos sobre los factores clave y valoración, asimismo, de la calidad actual de cada proceso. Esa consideración conjunta del impacto de los procesos sobre los factores clave y su calidad actual estimada ofrece un panel de criticidad que facilita a la Organización el conocimiento de qué procesos han de ser especialmente atendidos: mayor impacto y menor calidad presuponen, siempre, mayor criticidad (ver figura 33).

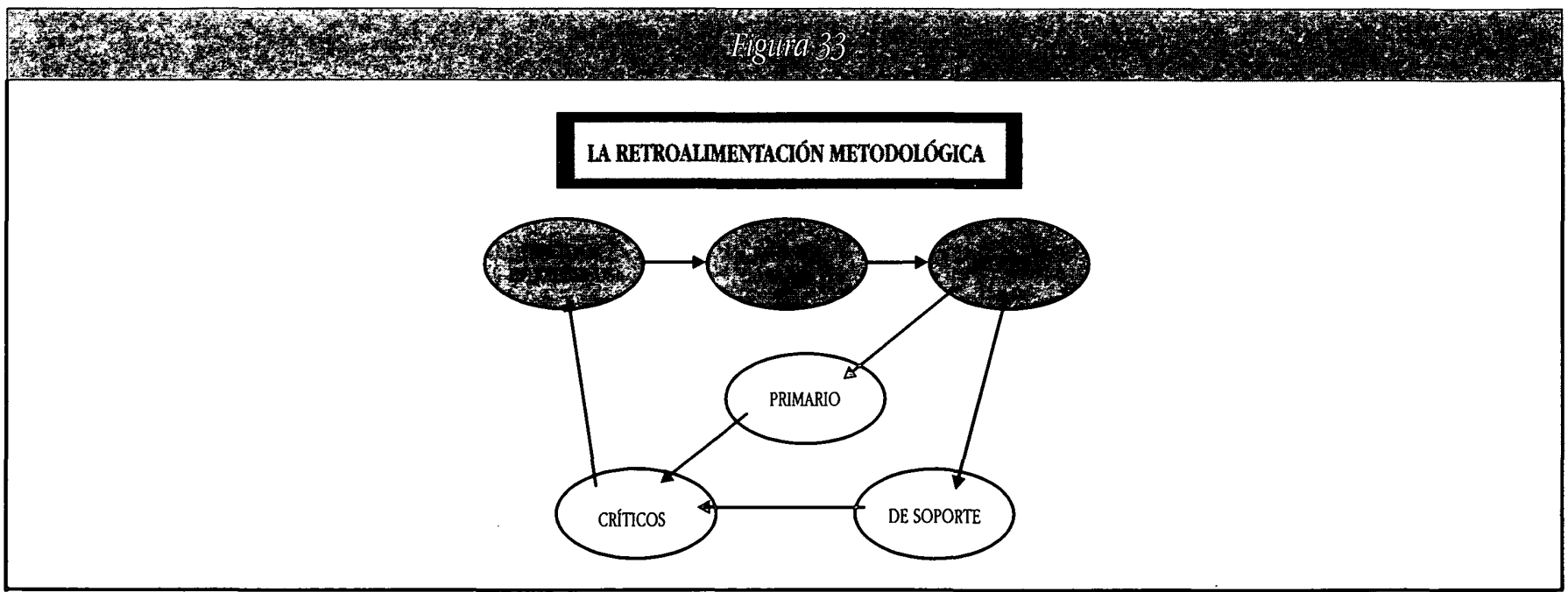


Modelo de referencia

La línea metodológica impuesta ha exigido, a continuación, el establecimiento de un panel de control del cambio en el quie queden específicamente detalladas tanto la visión que el Instituto tiene de su propio futuro como una puntual descripción de la que se considera su situación actual y, simultáneamente, el correspondiente desarrollo de las fases intermedias que permitan superar los GAP's establecidos entre aquellas situaciones.

Ese panel se constituye como un Modelo de referencia para la planificación a corto y largo plazo y permite evaluar y controlar, con la periodicidad deseada, los cambios que se decidan a nivel estratégico, manteniendo siempre la coherencia horizontal entre los contenidos de cada uno de los sistemas y elementos que conforman el GRID, configurado formalmente como una rejilla:

- Organización y cultura: Cultura y estilo de dirección; Organización, políticas y estrategias; Desarrollo y ges- tión de los Recursos Humanos; Tecnología y sistemas de información; y Relaciones con otras Organizaciones.

- Procesos: Gestión de prestaciones; Atención y asesoramiento al ciudadano; Planificación, control y seguimiento de la gestión; Asistencia técnica y juńdica; Gestión presupuestaria y contable; Gestión de recursos humanos; y Gestión de Recursos materiales.

- Sistemas y técnicas: Organización para la calidad y Herramientas de mejora.

Como puede observarse, el GRID, una vez cumplimentado en sus tres fases, acoge una visión sistémica de la Organización ordenando y contextualizando la posibilidad de un desarrollo organizativo global que, presidido por una dirección por políticas y prioridades, afecte al conjunto de iniciativas que han de desarrollarse para que una Organización como el INSS mantenga su posicionamiento en áreas avanzadas de calidad total (ver figura 34).

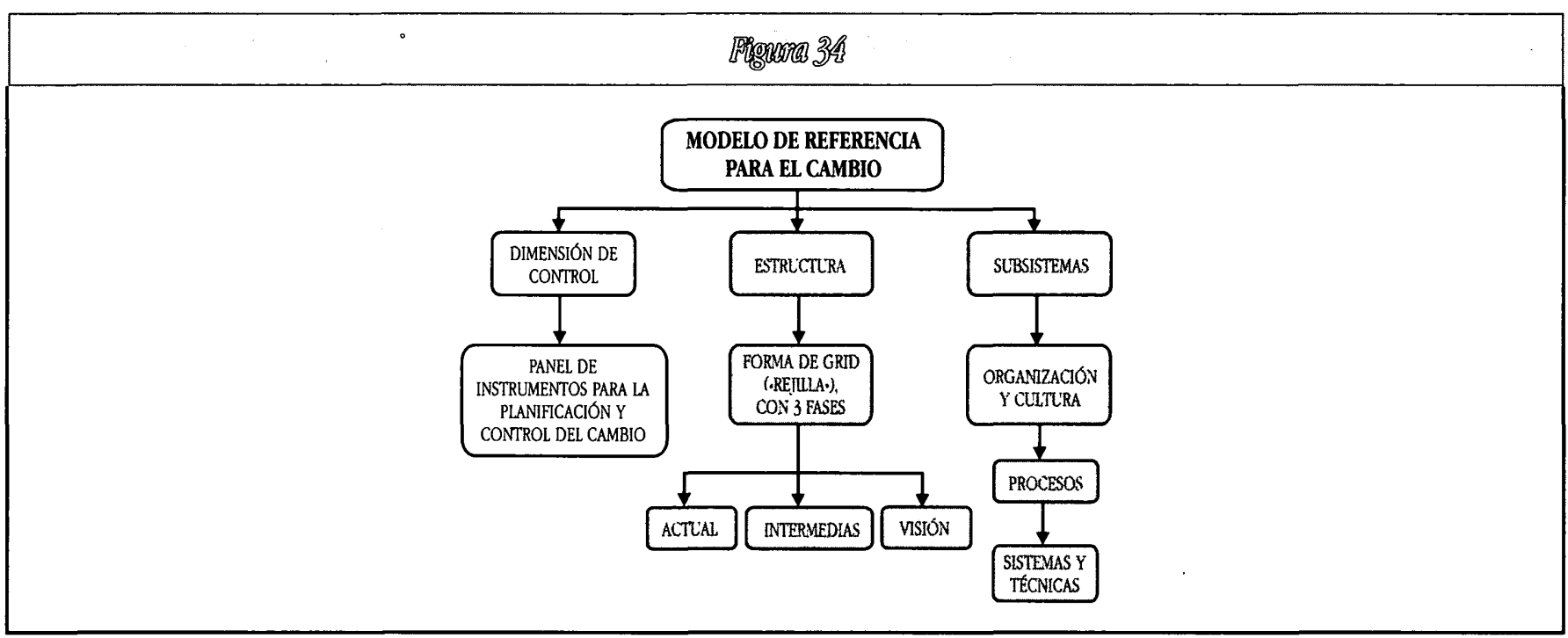

Fuente: NEGUERUELA (1998)

Apunte de reingeniería de procesos

El trabajo metodológico ha encontrado su última expresión en el establecimiento de unos GAP's de tránsito entre el proceso primario actual y su visión, que permite la utilización de instrumentos metodológicos cercanos a una específica, atenuada y singularizada reingeniería de procesos (ver figura 35).

Para ello se ha analizado el proceso actual desde una rigurosa descripción que contemplaba tanto los inputs y proveedores, como los actores, los outputs y los clientes, pasando por la determinación de los principales subprocesos, los indicadores del resultado final del proceso y los indicadores del control interno del proceso. El conocimiento de este proceso actual y las deter- minaciones anteriores permitieron establecer un sistema de macrobloques o fases para, a continuación, afrontar la visión del futuro proceso, con el establecimiento de sus fases óptimas y principios específicos que las presiden, así como los criterios organizativos del propio proceso. Desde esa prescripción se han podido afrontar los citados GAP's y establecer aquellas fases intermedias que posibilitarián transformar la actual gestión por funciones en gestión por procesos.

Todo lo anterior ha permitido, asimismo, establecer un apunte de objetivos de medición del proceso y determinar una serie de indicadores que siendo operativos puedan medir aspectos tales como la agilidad en el trámite, la ausencia de errores y la eficiencia del gasto (Negueruela, 1998). 


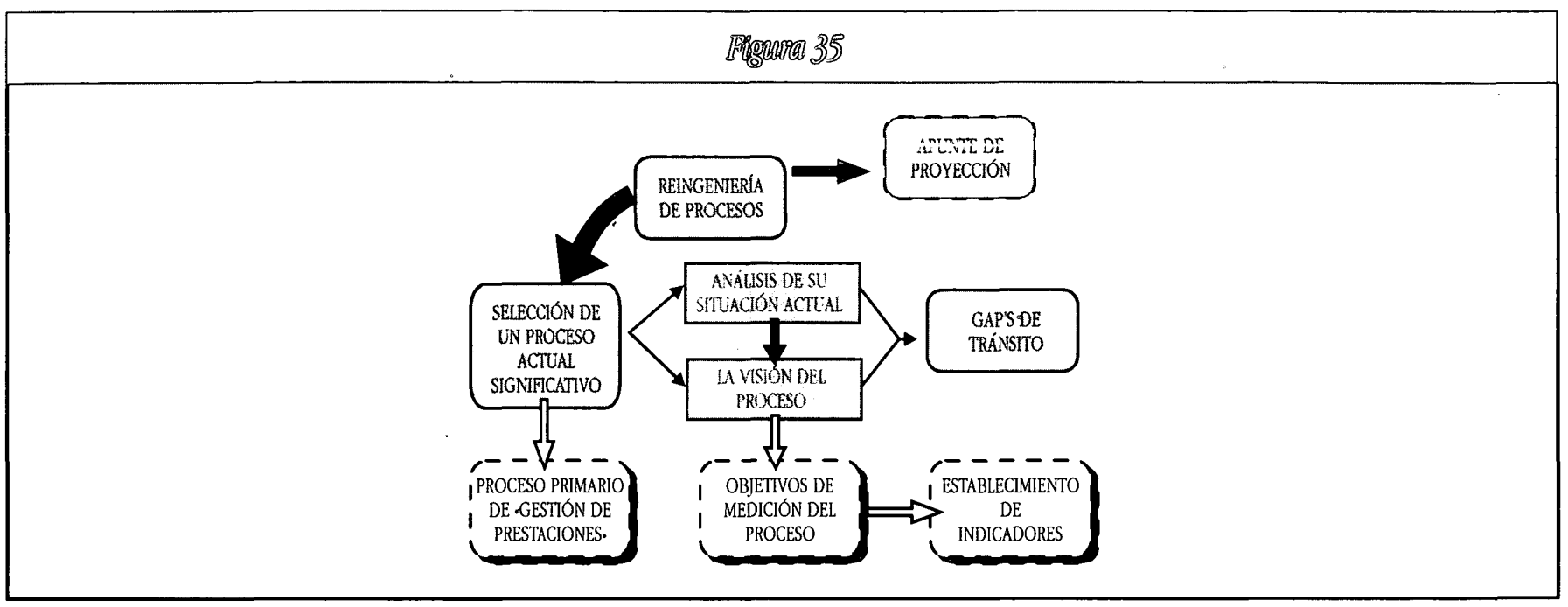

Fuente: NEGUERUElA (1998).

\section{El modelo de excelencia del INSS}

El trabajo metodológico desarrollado, desde los criterios que inspiran el Modelo Europeo de la EFQM, explicitado anteriormente, ha permitido diseñar, de forma singular y con las correspondientes adecuaciones, los distintos sistemas y elementos que integran su entramado organizativo. La referencia conceptual entre los sistemas y elementos que conforman el GRID de la organización y los agentes que integran aquel Modelo. El resultado de ese esfuerzo de integración conceptual permite que el INSS pueda presentar su propio proyecto de Modelo de Excelencia desde los parámetros conceptuales del vigente Modelo Europeo (ver figura 36).

\section{Proyección futura}

El estadio actual alcanzado en el Instituto posibilita un amplio campo de actuación en orden a completar y perfeccionar el camino metodológico iniciado. La intensidad de oportunidades de mejora que se presentan obligará a temporalizar y atemperar el proceso evolutivo de la Organización, desde la certeza intelectual de que su impulso se genera en ámbitos de rigurosa coherencia y meditada flexibilidad. En todo caso, la madurez del Instituto como organización pública directamente implicada en aspectos especialmente sensibles a la sociedad facilitará los impulsos de perfeccionamiento y mejora que, desde una planificación especificamente proyectada, han de mantenerle en posición avanzada en el camino hacia la excelencia organizacional; porque, en definitiva, el reto está ya planteado a pesar de que, en muchas ocasiones, «llegar a lo obvio, por evidente, pueda resultar revolucionario" (NEGUERUELA, 1998).

\section{Lecciones aprendidas}

A finales de la década de los 80, la Administración Central española lanzó un programa de modernización como parte de la ola reformista que afectó a otras democracias occidentales durante el mismo período. El programa intentó reformar el sector público español, pero los resultados han sido insatisfactorios y los principales objetivos no se han alcanzado. Sin embargo, las presiones de los ciudadanos para conseguir una Administración más eficiente no han disminuido (PARRADo-Díez y Ruzz-LóPEZ, 1997). El análisis somero de algunas de las razones que explican la poca virtualidad del programa de modernización, ya se han apuntado al comienzo de este trabajo y una mayor profundización requeriría acudir a otros autores (ALBA, 1995; BAÑON-MARTíneZ, 1993; Beltrán, 1995; Martín Mateo, 1994; Parrado-Díez, 1997; Pérez Menayo, 1996; Ruiz-López, 1996; Zapico, 1993; ...).

El caso concreto del INSS que hemos analizado es singular porque ha realizado un avance muy significativo en sus métodos de gestión y sigue progresando en mejorar la calidad de sus servicios y su evaluación, cuando todavía en muchos servicios públicos la modernización, con la consiguiente aplicación de metodologías de management reformado, sigue siendo más un asunto de debate y de trincheras que de plasmación práctica. Como destacan PARRADO y Ruiz (1997) el INSS sigue siendo un buen ejemplo de innovación y búsqueda de la calidad dentro de un idéntico marco legal en el que nos movemos todos los actores públicos, al que siempre se acude como excusa para explicar el encorsetamiento y la falta de dinamismo del sector público.

Estos autores han profundizado en el estudio específico del INSS y han encontrado los cimientos de los avances realizados desde 1996, analizados en este trabajo. Los aspectos siguientes del método de Halachmi (1995) son analizados, por Parrado y 


\section{Fregence 36}

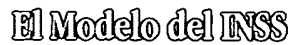

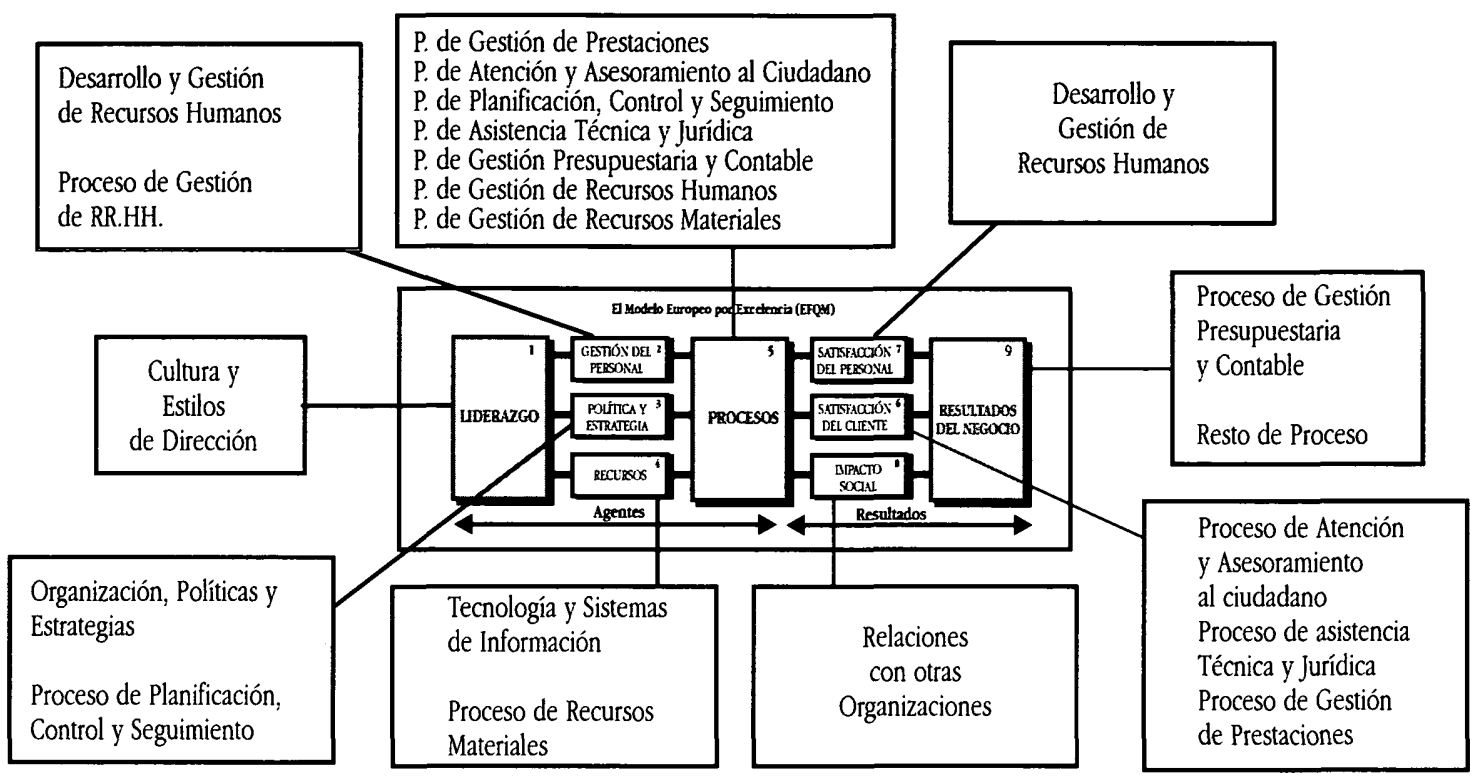

Ruiz, para el Instituto, y constituyen las fuentes que pusieron las bases de la situación actual de vanguardia del Instituto: compromiso desde los niveles más altos de la dirección (liderazgo fuerte y comprometido); obtención de nuevos recursos (altas inversiones en tecnología informática); una fuerza laboral motivada (la formación como instrumento estratégico de cambio); y la sensibilización de los medios de comunicación y de los usuarios de los servicios del INSS.

La planificación estratégica contribuye a la creación de una organización unteligenten, con capacidad de aprender colectivamente (SENGE, 1992). El cambio cultural ha de concebirse como un proceso de aprendizaje que permita a cada organización pública deshacerse de ideas y creencias que no se compadecen con lo que ocurre en el entorno' actual y requieren generar valores de recambio en consonancia con los nuevos sistemas sociales, a las puertas del tercer milenio. La clave de semejante transformación, aunque pueda sonar a tópico, consiste en movilizar el compromiso interno de los agentes públicos por los valores de la responsabilidad; esto supone una consideración prioritaria del papel de las personas.

Una de las suposiciones del management occidental consiste en sostener que los empleados no tienen posibilidad de influir por sí mismos en la calidad de los servicios que prestan sino que requiere un control externo para asegurarse. El movimiento de la Gestión de Calidad Total, con sus círculos de mejora y progreso, los grupos adbocráticos en suma (WATERMAN, 1993), se han encargado de mostrar que era posible lo que tales enfoques de racionalidad mecánica ni siquiera predecían o consideraban. La experiencia reciente del INSS de avance hacia un modelo eficiente de gestión de calidad, con sus grupos de compromiso institucional", "asesor" y "operativo", avalan el potencial, a veces inexplorado, que atesoran muchas organizaciones públicas.

Es difícil imaginar actualmente una organización pública que alcance sus objetivos sin valores y visiones compartidas por todos sus componentes, con una identidad y un sentido de pertenencia común. Cuando hay una visión aauténtica" (lo que la organización quiere ser en el futuro mediante procesos de cambio interno o de refuerzo del camino ya emprendido), los empleados públicos pueden motivarse ("entusiasmarse" podría ser un término de recambio) y se comprometen espontáneamente. El INSS como institución guarda en su memoria histórica etapas de ilusión colectiva. Recuperar y reforzar los valores implícitos en su cultura organizativa constituyen, hoy más que nunca, una exigencia de la entidad. Todo ello, ante los retos que tiene planteados nuestro sistema de protección social y el papel relevante que le corresponde jugar al Instituto como organización que gestiona, con calidad, más de siete millones de prestaciones económicas del Sistema de Seguridad Social.

Desarrollar una estrategia fructífera.como la apuntada en este trabajo, requiere elaborar una visión compartida por el mayor número de personas de la organización y ha de construirse en torno a varios principios clave:

- Toda organización tiene una misión, un propósito profundo que expresa su razón de ser. En estos momen- 
tos, se trataría del tránsito de una organización centrada en su propio funcionamiento, que ha incorporado la voz del cliente en su seno, a otra que fortalezca su auténtica misión. Se trataría de profundizar en dar el mejor servicio a los ciudadanos mediante el análisis periódico de sus expectativas y su comparación con las percepciones del servicio suministrado. Además, seguir segmentando de forma permanente el público objetivo del Instituto para acercarse cada vez más hacia sus necesidades, guardando el debido equilibrio con los fines del INSS como organización pública.

- No todas las visiones de los empleados son iguales. Ahora bien, las visiones que exploten un sentido profundo de la misión de la organización pueden poseer un poder singular para generar aspiración y compromiso por parte del personal. Para ser auténticamente compartidas, dichas visiones deben surgir de la reflexión de muchos funcionarios y empleados públicos sobre el propósito de la Entidad.

- Aquellos integrantes de la organización, especialmente los que se sienten más comprometidos, poseen un sentido colectivo de su misión. Este sentido compartido del propósito del INSS es tácito (MACK, 1995), está implícito en su cultura y se corresponde con un conocimiento del contexto en el que opera la Entidad; significa un conjunto de valores y creencias, de percepciones, de evaluaciones de la realidad. Explotar esta cultura colectiva sugiere preguntar a estas personas y aprender a escuchar las respuestas. El papel de los directivos consiste en hacer emerger esta expresión de la organización y no imponer su visión. Sólo así la visión es compartida y procura entonces un sentido a las acciones, a las políticas, que se emprendan. El contenido de una auténtica visión compartida sólo puede surgir de un proceso coherente de reflexión y comunicación interna.

Las lecciones de la experiencia en organizaciones públicas complejas, implicadas en procesos de mejora o de implantación de estrategias de calidad, sugieren que quienes pretendan liderarlas ni siquiera lo intenten sin haber sopesado seriamente todas las implicaciones, y que cuando inicien esta senda han de adoptar la decisión de realizarlas hasta el final. En el entorno público, a lo normativo de las reformas le ha sucedido, desde la modernización, la retórica de las reformas; así se agrada a la audiencia. En aquellas organizaciones sin propensión a la autoevaluación, los empleados no pueden aprender. No puede existir interés en cultivar la duda, el cuestionamiento, el esfuerzo de mejora continua, si la organización utiliza siempre los mismos datos, los mismos modelos, las mismas propuestas y las mismas técnicas de previsión. No basta compartir los datos, sino que es preciso compartir su lectura y apreciación. El enfoque de la calidad inspira cambios profundos con una aplicación duradera que se desplegará por toda la organización.

Ya a principios de la década de los ochenta, Ferguson afirmó que un cambio de paradigma implica trastorno, conflicto e incertidumbre. Los nuevos paradigmas son casi siempre recibidos con frialdad, incluso con burla u hostilidad. Aquellos que tienen intereses creados se oponen al cambio (jerarquía y statu quo obligan!). El cambio exige un punto de vista tan diferente sobre las cosas que los directivos "establecidos", a menudo son los últimos en acabar por convencerse, si es que se convencen; como afirma Ruskin (1994) "la calidad nunca es un accidente, sino el resultado de un esfuerzo inteligente.
- Secretario General del INSS.

' Este apartado ha sido elaborado con la colaboración del Área de Organización y Calidad del INSS.

? Asociaciones de pensionistas. Asociación para la Defensa del Pensionista (ADEPEN); Unión Democrática de Pensionistas y Jubilados (UDP); Confederación Nacional de Asociaciones de Jubilados y Pensionistas (CSI-CESIF); Federación Estatal de Jubilados y Pensionistas de UGT; Federación Estatal de Jubilados y Pensionistas de CC.OO; Confederación de Asociaciones de Jubilados y Mayores (CAJUMA).

Asociaciones de consumidores. Confederación Estatal de Consumidores y Usuarios (CECU); Organización de Consumidores y Usuarios (OCU); Unión de Consumidores de España (UCE).
Sindicatos. FSAP CC.OO.; UGT; CESIF.

${ }^{3}$ Este apartado ha sido posible gracias a la colaboración de Gregorio Negueruela Martínez, Jefe de la Inspección de los Servicios Centrales del INSS, y a los equipos que han realizado los primeros trabajos de requerimientos previos al Modelo EFQM.

${ }^{4}$ El INSS pertenece a la Asociación Española de la Calidad y desde 1997 ha sido acogido como miembro por el Club Gestión de Calidad de quien está recibiendo asesoramiento como organismo de enlace en España de la Fundación Europea para la Calidad (EFQM). Asimismo, el INSS, participa activamente en grupos de Benchmarking (emulación) en donde están representadas organizaciones públicas pertenecientes a las Administraciones Central, Autonómica y Local, así como diversas Empresas y Entes Públicos. 


\section{Bibliografia}

ALBA, C. (1995), ‘L'administration publique espagnole: Réforme ou modemisation?. Renne Francoise d'Administration Publique, n. ${ }^{\circ} 75$, pp. $387-401$.

ÁlVAReZ, C. (1998), sa lógica borrosa. Planeta Humano, n.ํ1, Madrid

ARGYRS, G. (1993), Cómo vencer las barreras onganizativas. Ed. Díaz de Santos.

asociación Española para la Calidad (1997), -Guía para la Gestión de Calidad de los Serivios Públicos (Adaptación norma ISO90042). Sección de Calidad en las Administraciones Priblicas, Madrid.

AzUA Mevdia (1991), La Calidad en la Administración Pública. Boletín Estudios Económicos, $\mathrm{n}$. ․ 143 .

BAENA, M. (1994), Organización, régimen jurídico y sector público estatal: La incidencia de las leyes de presupuestos. A. PÉREZ (ed.), Administración instrumental: Libro bomenaje a Manuel Francisco Clavero Arévalo, Civitas. Madrid, pp. 71-102.

BAGozzl, R. (1975), Markéting Exchange. Joumal of Marketing, vol. 39, American Marketing Association.

Bẫón MartíneZ, R. (1993), -La modemización de las administraciones públicas espanolas: Balance y Perpectivas. Politica y Sociedad, n.․ 13, pp. 9-21.

BAROUCH (1994), •Un deuxième soufle pour la modernization des administrations d'État: analyses et propositions", Revue Politiques et Management Publique, vol. 12, n. 4 .

BARZEIAY, M. (1992), Breaking through bureaucracy. University of California Press, Berkeley.

BELTRÁN, M. (1995), .La reorganización de la estructura del Estado (1982-1993). Informe FOESSA 1995 (Informe sociológico sobre la situación social en España). Fundación FOESSA, Madrid.

BerRY; BenNet y BRown (1989), Calidad de Servicio. Ed. Díaz de Santos.

BizCARRONDO, A. (1992), "Agencia Estatal de Administración Tributaria". En Calidad Total en los Servicios Públicos y en la Empresa, MAP, pp. 132-133.

Box, C. (1990), :Promesa y límites del policy analysis en Estados Unidos". Documentación Administrativa, n. ${ }^{\circ}$ 224-225, octubre 1990-marzo 1991. Numero monográfico relativo a •Políticas Públicas y Organización Administrativar.

_. (1994), •Hacia una Administración Pública eficaz: modelo institucional y cultura profesional en la prestación de servicios públicos. GAPP n. ${ }^{2} 1$, Madrid.

BrockMav (1993), Total Quality Management: comparación entre USA y el Reino Unido. IEF. Tradución de REINA BITAR.

BRUGuÉ; Amorós y Gomà (1994), La Administración Pública y sus clientes: ¿̇moda organizativa u opción ideológica?. GAPP, n. ${ }^{2} 1$.

BRUNEL UNIVERSTY (1993), The Valuation of Changes in Quality in the Public Services: Repor Prepared for H.M. Treasury by Brunel University. HMSO, London, citado por POLUT y BOUCKAERT (1995).

Campanella, J. y Corcoran, F.I. (1993), "Los principios de los costes de calidad. En Cambio tecnológico y Contabilidad de Gestión, en Instituto de Contabilidad y Auditoría de Cuentas, Ministerio de Economía y Hacienda.

CANALES ALIENDE, J.M., sLa demanda de producción de bienes y servicios y la concepción del administrado como cliente en el proceso de modernización administrativa. REGAP, n. .5 .

Carmona, S. (1993), Curvas de olvido y sistemas de información. Instituto de Contabilidad y Auditoría de Cuentas, Ministerio de Economía y Hacienda.
CARR, O. y LITTMAN, J.D. (1990), Excelence in Governement: Total Quality Management in the 1990. Alligton, UA, Coopers \& Lybrand (cit. SWIS, op. cit).

CeBriáv, J.L. (1998), ·la red. Cómo cambiarán nuestras vidas los nuevos medios de comunicación. (Un informe al Club de Roma), Ed. Taurus Pensamiento.

CEPPP (1992), Considering Quality: an Analytical Guide to the Literature on Quality and Standards in the Public Services. Centre for the Evaluation of Public Policy and Practice, Brunel University, Uxbridge; citado por Pourt y BoucKaERT (1995).

_(1994), An Evaluation of Total Quality Management in the National Health Senvice: Synopsis of the Final Resport to the Department of Health. Centre for the Evaluation of Public Policy and Practice, Brunel University, Uxbridge.

CHIAS, J. (1995), Marketing Publico. Por un gobierno y una administración al servicio del puiblico. Mc Graw Hill, p. 44.

Club de Roma (1998), ‘La red. Como cambiarán .... Ver Cebrián, J.L. (1998).

CROSBY, P. (1979), Quality is Free. McGraw-Hill, New York.

(1987), La calidad no cuesta. Díaz de Santos.

_ (1988), The Etermally Successful Organization. McGraw-Hill, New York.

Crozier, M. (1964), El fenómeno burocrático. Ed. Seuil.

_(1970), La société bloquée. Ed. Seuil.

_(1974), Où va l'administration française? Les Editions d'Organisation.

(1995): «La posición del Estado ante los otros actores». GAPP, n.ำ 2, p. 96.

DAHLGAARD, J.I. (1993), •Un estudio comparativo de los métodos y principios de control de calidad en Japón, Corea del Sur y Dinamarca. En Cambio Tecnológico y Contabilidad de Gestión, Instituto de Contabilidad y Auditoria de Cuentas, MEH.

DE Geus, Arie (1988), ·Planning as Learning. Harvard Bussiness Review.

Deming, M.E. (1989), Calidad, Productividad y Competitividad. Díaz de Santos, Madrid.

DroIN, R. (1993), La calidad a través de la sonrisa. Ed. Deusto, Bilbao.

DRUCKER, P.F. (1978), The Age of Discontinuity. Nueva York, Harper Torchboods.

DunleaVy, P. y HoOD, C. (1995), •De la Administración Pública tradicional a la nueva Gestión Pública. Ensayo sobre la experiencia modemizadora de diversos países desamollados. GAPP, n. 3 .

ECHEVARRía, K. (1993), ‘La Administración Pública en la era del management• (Tesis doctoral).

EUROPEAN Foundation FOR QuAuTY MANAGEMENT (EFQM, 1996), Autoevaluación. Directrices para el Sector Püblico. Club Gestión de Calidad.

Ferguson, M. (1985), La conspiración de Acuario. Transformaciones personales y sociales en este fin de siglo. Ed. Kairós, Barcelona.

FundaCión EUROPEA PARA LA MEJORA DE LAS CONDICIONES DE VIDA Y DE TRABAJO (1991), Servicios Públicos: trabajar para el consumidor. C.E. Luxemburgo.

Gálgano, A. (1993), Calidad Total. Díaz de Santos, Madrid.

(1995), Los siete instrumentos de la Calidad Total. Díaz de Santos, Madrid. 
GAllego GIL, D. y ALONSO, C. (1995), ،La organización que aprende: un enfoque proactivo para un contexto de calidad y competitividad. Capital Humano, n. 94 .

Garlavd, R. (1996), Trabajar y Dirigir en la New Age. Ed. Granica, Barcelona.

Garde RoCA, J.A. (1992), Calidad Total en los Servicios Públicos. MAP, pp. 191-193.

; Pérez Menayo, V. y Bartolomé, J. (1996), .La Gerencia Pública como integración*. En la obra colectiva. Lecturas de Gerencia desde la Administración Financiera, Instituto de Estudios Fiscales, Ministerio de Economía y Hacienda, Madrid. IEF

y ZAPICO (1995), .Presupuesto en Base Cero "limitado". Cuadernos de Actualidad

GARRAT, B. (1990), Creating a Learming Organization. A Guide to Leadship Learning Development. Cambridge.

(1992), Creating a Learning Organization: Top management rule. Formación y Empresa. Revista Institucional de EADA, n.. 33 , primer trimestre.

GARVIN, D.A. (1993), •Building a Learning Organization, Harvard Bussiness Review.

GIBERT y THÖENING (1993), •La gestión publique: entre l'apprentissage et l'amnésie. Revue Politiques et Management Publique, vol. 11, n. ${ }^{1} 1$.

GOBERNA, R. y TREBESH, K. (1994), Presente y futuro del aprendizaje organizacional: la práctica de la teoría. XV Jornadas Nacionales de AFYDE, Palma de Mallorca.

GONZÁlEZ-POSADA, A. (1994), ‘El Instituto Nacional de la Seguridad Social: Una organización al servicio de sus clientes. GAPP, n.․⒈

GyFoRD, J. (1991), Citizens, Consumers and Councils, McMillan, Londres.

HalaCHMI, A. (1995), sIs TQM ready for the public sector?. En A. HALACHMI y G. BOUCKAERT (eds.), Productivity tbrougb quality and strategic management, Amsterdam: IOS Press; citado por PARRADO y RUIZ (1997).

HEDBERG Y JöNSSON (1993), Diseño de sistemas de información semiconfusos para organizaciones en entornos cambiantes. Instituto de Contabilidad y Auditoría de Cuentas, Ministerio de Economía y Hacienda.

Hermel y ROMAGNI (1990), Le Marketing Public. Ed. Economia, pp. 8-9.

HOOD y Wright (1981), citado en POLLIT y BOUCKaERT (1995), Bruselas.

IMAI, Masaaki (1989), Kaizen. Compañía Editorial Continental, S.A., Mexico.

JimÉNEZ, E.; BARREIRO, F y SÁNCHEZ, J.E. (1998), Los nuevos yacimientos de empleo. Ed. Fundación CIREM

JURÁN, J.M. (1990), Jurán y el liderazgo para la calidad y Jurán y la planificación de la calidad. Díaz de Santos.

KETTL, D.F. (1994), •Más allá de la retórica de la reinvención: una reflexión sobre las reformas Clinton de la Gestión Pública. GAPP, n.ํ? 3 .

KLIKSBERG, Bernardo (1989), ¿Cómo será la gerencia en la década del 90? CLAD.

Kosko, B. (1998), Universidad de California del Sur. Entrevista de ÁLvarez, C. (1998), La lógica Borrosa.

KotLeR, P. (1975), Marketing for non Protit Organizations. Ed. Prentice Hall.

(1992), Dirección de Markéting. Ed. Prestige Hall.

(1993), •Pour une reussite du marketing des services publiques dans les années 90. Reune Politiques et Management Publique, vol. 11, n. .2 .
LANDAU, M. y CHISHOLM, D. (1993), sLe management de l'administration publique doitil être orienté vers la réussite ou chercher à eviter les échecs? Un réexamen. Revne Politiques et Management Public, vol. 11, n. ${ }^{\circ} 1$.

LAURENCE, P. (1985), Por qué las cosas salen mal; o retorno al Principio de Peter. Plaza y Janés.

Llavo, A. (1989), La empresa ante la nueva complejidad. Fundación Humanismo y Empresa, Universidad de Navarra.

LYNN, L. (1993), •Management sans managers: les fausses promesses des reformes administratives. Revue Politiques et Management Public, vol. 11, n. .1 .

LOPEZ MarTíneZ, A. (1993), ‘Gestión de la Calidad Total en la Administración Pública Española. ICE, n. 924 .

LOUPPE, A. y MENGUY (1978), :Approches pour definir un marketing public. Revue Française d'Administration Publique, abril.

MACK, M. (1995): «L'organisation apprenante comme système de transformation de la connaissance en valeur. Revue Française de Gestion, n. ${ }^{0} 105$

_y BAUMARD, P.L. (1995), ‘Des organizations apprenants? Les dangers de la consensualitér. Revue Française de Gestion, n. 105.

MacNeilL, D y Freiberger (1998), Fuzzy Logic (Lógica borrosa), citado por Álvarez, C. (1998)

MAP (1995), Cartas de Servicios Públicos. Documentos INAP.

MARTín MATEO, R. (1994), •El sistema administrativo clásico y su permeabilidad a los nuevos paradigmas de la Calidad Total. Revista de Administración Pública, n. ${ }^{1} 134$.

Meru, G. (1995), La Calidad Total como Herramienta de Negocio. Díaz de Santos.

(1995), Managing by Priority. Ed. Wiley, England.

__(1995), El Directiu Emprenedor. Ed. Columna, Barcelona.

(1997), La Gestión Eficaz. Díaz de Santos.

_

METCALFE, Les y RICHARDS, Sue (1989), La modernización de la Administración Pública. MAP, pp. 71-73.

MICKLETHWAIT, J. y WOOLDRIDGE, A. (1998), La bora de los guris. Alianza Editorial, Madrid

MORIN, E. (1990), Introducción a la pensée complèxe. ESE.

NAISBITT, J. (1998), Global Paradox. Jornadas profesionales de ESIC, Madrid. __ y ABURDENE, P. (1986), Reinventar la empresa. Ed. Folio, Barcelona.

_y ABurdene, P. (1990), Megatrens 2000. Ed. Actualidad Libros, Barcelona.

NEGUERUELA, G. (1998), Una metodología avanzada para la gestión eficiente del INSS. IX Congreso de Calidad, Forum de Empresas, Barcelonà.

OCDE (1991), La Administración al Servicio del Público. MAP; Serving the Country Better (1985), Irlanda; Public Service 2000 (1990), Canadá.

OLIETE CABESTRÉ (1998), Calidad del Servicio: como medir la satisfacción del cliente. Congreso de Calidad Asociación Española de Calidad, Madrid.

ORGogozo, I. (1987), Les paradoxes de la qualité. Editions d'Organisation.

OSBORNE y GaEBler (1994), La reinvención del Gobiemo. Ed. Paidós. 
Ouchi, W. (1985), La teoria Z, Obis.

Parasumaray; ZetThmal y BerRy (1993), Calidad total en la gestión de los senvicios. Díaz de Santos.

ParRado-Dífz, S. y Ruiz-López, J. (1997), •El camino de la calidad en un organismo autónomo espanol. Public Productivity-Management Review, SAGE.

Pérez MeNayo, V. (1996), Modernización de las Corporaciones Locales: Nuevos Enfoques. 5.5 Xomadas Galegas sobre Economía das Corporacións Locais, Xunta de Galicia.

(1998), El Front Office con el ciudadano: cómo mejorar la atención al ciudadano. Civex'98: Reforma, modemización y gestión del cambio en las Administraciones Públicas, Madrid.

y BarTOlomÉ, J. (1993, 1994, 1995), Manuales de formación en •Calidad y Servicio al Contribuyente; - La atención al ciudadano en la AEAT; :La atención al ciudadano en el centro de Gestión Catastral y CT; ‘ ‘estión de Calidad en las Administraciones Públicas. Escuela de Hacienda Pública (IEF).

y Bartolomé Llorente, J. (1995), ·Técnicas de Dirección. Enfoque de Habilidades. Curso de Gerencia Pública, Instituto de Estudios Fiscales.

_y Bartolomé, J. (1996), ‘la Gestión de Calidad Total y su aplicación a la Administración Pública y ·Teoría y Técnicas de Comunicación: su aplicación a las Administraciones Públicas. En la obra colectiva: Lecturas de Gerencia desde la Administración Financiera, Instituto de Estudios Fiscales, Ministerio de Economía y Hacienda, Madrid.

y BARTOLOMÉ, J. (1996), Gestión de Calidad y Austeridad en la Administración Pública. Ponencia Jomadas sobre «Austeridad en el Gasto Público", Santiago de Compostela.

Peters, T. y Waterman, R (1989), En busca de la excelencia. Ed. Folio.

PoLuT, C. (1993), El Gerencialismo y los Servicios Píblicos. La experiencia anglo-americana. IEF, Madrid.

y BoucKaERT, G. (1995), Quality Improvement in European Public Services. Sage Publications, London.

POPCORN, F. (1993), Lo que vendrá. Ed. Granica, Barcelona, p. 114.

RICHARDS, S. (1994), •El paradigma del cliente en la gestión pública. GAPP, n.ำ 1.

REIX, Robert (1995), Savoir tacite et savoir formalisé dans l'entreprise. Revue Française de Gestion, n. ${ }^{\circ}$ 105, sept. oct.

RÖBER, M. (1989), •Posibilidades y límites del marketing público. Documentación Administrativa, n. ${ }^{\mathrm{s}} 218-219$, pp. 437.

RUIZ-LÓPEZ, J. (1996), Evaluación de la calidad en la Administración del Estado: La experiencia del Observatorio de la Calidad de los Servicios Príblicos. Ponencia presentada en el Congreso Internacional de Evaluación de la Calidad (Comisión Europea, Asociación para la Evaluación de la Calidad y Universidad Complutense de Madrid).
RuskTN, J. (1994), citado por SADERRA JORBA, L.L. (1995), La Calidad Total. Ediciones técnicas Rede, S.A., Barcelona.

SADERRA JORBA, L.L. (1995), La Calidad Total. Ediciones técnicas Rede, S.A., Barcelona.

SEVGE, Peter (1992), La quinta disciplina: cómo impulsar el aprendizaje en la organización inteligente. Ed. Granica.

(1995), La quinta disciplina en la práctica. Estrategias y berramientas para construir la organización abienta al aprendizaje. Ed. Granica.

SExLle, A. (1993), •Calidad Total en los Servicios y en la Administración Pública, Gestión 2000.

SERIEYX, H. (1991), El desprecio cero. Hacia la calidad total. Mc Graw-Hill.

(1994), El big-bang de las organizaciones. Ed. B. Grupo Zeta.

STEWART, J. y RanSon, S. (1994), Management for the Public Domain. MacMillan, Basingstoke; citado por Polut y BouCKAERT (1995).

StRAnd, T. (1984), Public Management, Conceptual Issues and Research Suggestions. Presentado a la conferencia ePublic Management in Europen, La Haya.

SuBiRaTS, J. (1990), ·La Gestión Pública en los 90: nuevos retos y oportunidades. Encuentro sobre «Ia gestión de la Seguridad Social de los 90, Benicarló.

SwISS, J. (1992), La adaptación del Total Quality Management (TMQ) a la Administración. Public Administration Review, vol. 52, n. 4

TAPSCOTT, D. (1998), ‘Promesas y Peligros de la Tecnología digital. Prefacio a la obra de CeBRí́. J. J.L. (1998), La red. Un informe al Club de Roma.

TOFFLE, Alvin (1978), Anticipatory Democracy. Vintage Books, Nueva York.

(1980), La tercera ola y El shock del futuro. Ed. Plaza y Janés.

(1990), El Cambio del Poder. Plaza y Janés.

Trosa, S. (1995), Quality in the French Public Service, citado por POLLT y BOUCKAERT (1995).

WATERMAN, R.H. (1993), Adbocracia, Ariel, Barcelona.

WildaVsky (1975), citado por PÉrez Menayo, V. y Bartolomé, J. (1996), Gestión de Calidad y Austeridad en la Administración Pública, Xunta de Galicia.

WINKLER (1998), citado en POLLIT y BOUCKAERT (1995).

ZAPICO, E. (1993), .Le pointeur: La modernisation de l'administration publique espagnole. Revue Française d'Administration Publique, n. .66 , pp. 309-319.

—y MAYNE (1995), Nuevas perspectivas para el control de gestión y medición de resultados. GAPP, n.? 3 . 


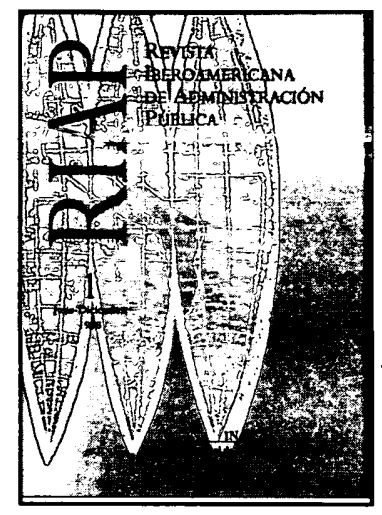

La ReVISTA Iberoamericana de Administración Pública, RIAP, es una nueva publicación semestral del Instituto Nacional de Administración Pública de España a través de la cual el INAP, continuando su tradición de acercamiento y colaboración con los países iberoamericanos, pretende crear nuevos vínculos de relación y cooperación entre las Administraciones Públicas de España e Iberoamérica.

Concebida como un foro abierto para la cooperación y el intercambio de información, opiniones y experiencias en el ámbito Iberoamericano de la Gestión Pública y las Ciencias de la Administración, la Revista Iberoamericana de Administración Pública, cuenta con un Consejor Rector Institucional presidido por el Ministro de Administraciones Públicas de España y con un Comité Científico integrado por destacados profesores e investigadores universitarios de Iberoamérica y de España.

La nueva Revista cuenta con un Índice estructurado en torno a cuatro Secciones: Artículos, Experiencias, Noticias y Documentos, dentro de los cuales tienen cabida desde las reflexiones doctrinales, hasta las crónicas de actualidad, el intercambio de informaciones sobre experiencias y actividades y la publicación de dossieres y documentos de interés mutuo.

Con todo ello, y mediante esta nueva publicación, el INAP de España desea continuar sus líneas de actuación respecto de Iberoamérica en las que a su misión institucional se le unen su vocación y su compromiso de presencia y colaboración con sus Administraciones Públicas.

\section{Director}

D. Enrique Álvarez Conde

\section{Secretario}

D. Jorge Urosa Sánchez

\section{Coordinación}

Centro de Publicaciones del INAP

\section{Edita:}

MINISTERIO DE ADMINISTRACIONES PÚBLICAS

Instituto Nacional de Administración Pública

ISSN: $1139-3750$

NIPO: 329-98-006-5

Depósito Legal: M-32.859-1998

Imprime: Rumagraf, S.A.

Avda. de Pedro Díez, 23. 28019 Madrid
Suscripciones y Administración:

Instituto Nacional de Administración Pública

Centro de Publicaciones

Atocha, 106. 28012 Madrid

Teléfono: 913493115 - 3235

Precios:

Fax: 913493287

E-mail: publicaciones@inap.map.es 